Anuario de Estudios Medievales

43/2, julio-diciembre de 2013, pp. 505-541

ISSN 0066-5061

doi:10.3989/aem.2013.43.2.01

\title{
EL ESPACIO PECUARIO EN MEDELLÍN (1450-1550)
}

\author{
THE GRAZING SPACE IN MEDELLÍN (1450-1550)
}

\author{
Julián Clemente RAmos \\ Universidad de Extremadura
}

Resumen: El espacio pecuario de Medellín se compone de comunales y dehesas. La coyuntura de crecimiento que se desarrolla en los siglos XV y XVI influye fuertemente en su configuración: ampliación de las dehesas boyales, proliferación de cercas en los ejidos, desarrollo de cultivos en las dehesas, conformación de las hojas de cultivo. Las aldeas, con una base hacendística muy limitada, arriendan de forma creciente los pastos comunales. En Medellín, los propietarios de dehesas sólo han podido acotar el pasto. Los vecinos aprovechan la bellota, muy importante para la cabaña porcina, y el monte.

Palabras clave: espacio ganadero; comunales; dehesas; usos comunales; baja Edad Media; siglo XVI.

\begin{abstract}
The pasture land of Medellín consists of communal lands and dehesas. The period of growth that took place during the 15 th and 16th centuries had a strong influence on its configuration: the enlargement of the dehesas boyales, the proliferation of fences in the ejidos, the cultivation developments in the dehesas and the formation of fields. The villages, which had a weak fiscal base, increasingly leased the communal pastures. In Medellín, the owners of the dehesas had only appropriated the grass; the neighbors took advantage of the acorn, a very important resource for the pork-based livestock, and the woodland.
\end{abstract}

Keywords: grazing space; public lands; dehesas; communal uses; Late Middle Ages; Sixteenth century.

\section{SUMARIO}

1. Introducción.- 2. La propiedad comunal y concejil.- 2.1. Ejidos.- 2.2. Dehesas boyales.- 2.3. Arriendo de pastos comunales.- 2.4. Los propios.- 3. Las dehesas.3.1. Estructura y difusión espacial.- 3.2. La explotación del monte.- 3.3. La montanera.- 4. El terrazgo cerealista: rastrojos y derrota de mieses.- 5. Espacio pecuario y crecimiento económico.- 6. Conclusiones.- 7. Bibliografía.

${ }^{1}$ Proyecto HAR2010-15238, del Ministerio de Economía y Competitividad. Abreviaturas utilizadas: AGS-CR = Archivo General de Simancas, Consejo Real; AGS-CCP = Archivo General de Simancas, Cámara de Castilla, Pueblos; AHN = Archivo Histórico Nacional; ACG = Archivo de la Chancillería de Granada; AMG = Archivo del Monasterio de Guadalupe. 


\section{INTRODUCCIÓN}

El interés en el espacio pecuario ha sido una constante en la investigación medieval española debido a la importancia de la ganadería y de su registro documental. Son numerosas las publicaciones que de modo monográfico o dentro de una investigación más amplia han incidido sobre esta temática. Muchos aspectos, sin embargo, han sido abordados de modo insuficiente y/o inadecuado ${ }^{2}$. En un estudio más amplio que intenta abordar de modo global la ganadería en un espacio local (Medellín) a finales del periodo medieval y comienzos del moderno, nos ha parecido adecuado tratar de forma sistemática el espacio que sustenta este sector productivo. Estamos ante una realidad que tiene una enorme incidencia paisajística en la submeseta meridional y específicamente en Extremadura. Nos hemos apoyado en una información rica aunque temporalmente discontinua.

El espacio pecuario de Medellín se fija en sus líneas generales, como hemos estudiado, durante el proceso de ocupación y explotación cristiana del territorio. Un rasgo destaca de forma clara: la enorme difusión espacial del adehesamiento, fenómeno con incidencia no sólo paisajística y económica sino también sociopolítica. Este fenómeno va a reducir el espacio comunal, que tiene un enorme peso en otras jurisdicciones ${ }^{3}$. Aunque no disponemos de datos precisos, podemos de todos modos señalar su modestia en términos relativos.

En los siglos XV y XVI, el espacio pecuario sufre cambios importantes debido a la coyuntura de crecimiento demográfico y agrario. Contamos para su estudio, respecto de periodos anteriores, con una documentación más rica y sobre todo más precisa proveniente sobre todo de fuentes procesales. Algunos aspectos pueden ser abordados con cierto detalle y presentan, como los derechos comunales sobre las dehesas, una notable novedad.

En las páginas que siguen vamos a intentar a abordar de modo sistemático las formas de explotación y los cambios que sufre el espacio pecuario de la tierra de Medellín. Estamos sin duda ante una realidad compleja que abarca espacios de titularidad concejil-vecinal (comunales, propios) y privada (dehesas, terrazgo cerealista) sobre los que se desarrollan mecanismos de aprovechamiento muy diversificados. Los cambios económicos e institucionales van a producir transformaciones en su extensión, perfil paisajístico

\footnotetext{
${ }^{2}$ Una perspectiva general con bibliografía en E. Rodríguez-Picavea, La ganadería en la Castilla medieval, pp. 111-153, y $\mathrm{M}^{\mathrm{a}} \mathrm{C}$. Gerbet, Un elevage original, pp. 393-413.

${ }^{3}$ El espacio baldío o comunal representa una parte sustancial de los términos concejiles, como lo avalan algunos datos tardíos: L.V. Pelegrí, A.D. Martín: Tierra y sociedad en La Serena, p. 65; M.A. Melón, Extremadura en el Antiguo Régimen, pp. 277-278.
} 
o modos de explotación. Como en muchas otras realidades bajomedievales, estamos ante elementos que en su mayor parte tendrán una larga vigencia temporal.

\section{LA PROPIEDAD COMUNAL Y CONCEJIL}

El espacio comunal en la tierra de Medellín se vio condicionado negativamente por la extraordinaria importancia del adehesamiento. No disponemos, ni siquiera tardíamente, de datos precisos sobre su extensión. Los bienes desamortizados de Medellín y sus aldeas (excluida Miajadas) alcanzaron 7.857 hectáreas. A ello hay que unir 23.864 hectáreas de baldíos comuneros, de los que 17.246 hectáreas pertenecen a arbolado de dehesas particulares ${ }^{4}$. La importancia de estos espacios, en todo caso, queda fuera de toda duda.

El espacio comunal no forma una unidad. Los comunales en sentido estricto se aprovechan por los vecinos sin compensación alguna. Los propios, sin embargo, forman parte de los recursos hacendísticos concejiles y se ceden en arriendo. Entre los primeros podemos distinguir dos tipos en función de las condiciones de acceso a su explotación: los comunales de la tierra, citados frecuentemente como baldíos, y los comunales de los diversos núcleos de población, villa o aldeas ${ }^{5}$. En teoría, el primer grupo abarca todos aquellos espacios que no forman parte de los términos locales o de las dehesas. Estos espacios aparecen muy escasamente en la documentación. Su estudio exigirá un rigurosa metodología regresiva y el uso sistemático de fuente modernas y contemporáneas. Los términos de cada población, en líneas generales de carácter circular, están formados por el ejido, la dehesa boyal y el terrazgo agrario. Se trata de comunales reducidos y adscritos a usos muy precisos. Alonso Sánchez Moreno (Mengabril), aludiendo de modo implícito a los dos tipos de comunales señalados, afirma que los ganados de la tierra pueden acceder a todo el pasto que los vezinos de Mengabril tovieren fuera de la dehesa boyal y exido ansarero... porque es costunbre en este condado 6 .

${ }^{4}$ J.A. Ruiz, Evolución de la propiedad de la tierra, pp. 286 y 288, cuadros 60 y 61.

${ }^{5}$ Sobre situaciones similares: J.M ${ }^{\mathrm{a}}$ Monsalvo, Espacios de pastoreo, pp. 158 y 165-166; N. Salomon, La vida rural castellana, pp. 131-138; M. Diago, Aprovechamiento de baldios y comunales, pp. 418-419; E. Pérez, Patrimonios comunales, pp. 186-188.

${ }^{6}$ AGS-CR, leg. 526, exp. 5, f. 77v. Los comunales de aldea tienen un modesto desarrollo, frente a la omnipresencia de los de la villa y tierra. Una realidad distinta se documenta en algunos concejos meseteños: $c f$. J.M Monsalvo, Espacios de pastoreo, pp. 168-169; $\mathrm{M}^{\mathrm{a}}$ Asenjo, Segovia. La ciudad y su tierra, pp. 168-169. 


\subsection{Ejidos}

El ejido o ejido ansarero rodea los núcleos de población y se destina al mantenimiento de la cabaña vecinal ${ }^{7}$. El de Guareña, según los procuradores de la aldea, se extiende aderredor del dicho lugar cantidad de un tiro de ballesta segund como lo tienen todos los otros lugares... de Medellín ${ }^{8}$. Según Pedro Martín Peinado, los ejidos ansareros son pequeños porque solamente son para casas e corrales e criar algunos puercos ${ }^{9}$.

El ejido queda reservado estrictamente para la cabaña local. A esto se refiere Juan Román de la Pompa cuando afirma que se guardan los hexidos ansareros de cada lugar (a. 1548). Juan Jiménez, en el mismo sentido, sostiene que no pueden pastar ningunos ganados de los vecinos de la dicha billa del Medellin ni de los lugares de su termino en los exidos de ningun lugar ${ }^{10}$. Retengamos la vinculación entre ejidos y cabaña vecinal.

Valdetorres y quizás también Don Llorente parecen presentar una situación diferente. Se trata de poblaciones que surgen en heredades de los Mejía y en las que se ha intentado constituir señoríos solariegos y jurisdiccionales con resultado desigual. El regidor Pedro García tenía por ejido todo el término de Valdetorres. En términos parecidos se expresa el alcalde Francisco Herrero $^{11}$. El concejo de Valdetorres considera que todo su término y el de Don Llorente es ejido y lo hace derivar de la renta que paga a los propietarios ${ }^{12}$.

Los ejidos presentan importantes cambios en los siglos XV y XVI. Serán objeto preferente de numerosas apropiaciones. Los cercamientos, derivados de su carácter inicialmente ganadero, irán adquiriendo un peso creciente. Se reduce, de este modo, el espacio susceptible de aprovechamiento pecuario. Hemos conservado para la cuarta década del siglo XVI información sobre más de un centenar de apropiaciones en el ejido de Miajadas. Según una probanza de la tierra, en 1538 se derribaron en el ejido treçientas çercas y mas $^{13}$. Los concejos tenían costumbre de dar pequeños espacios para solares o cercas. A principios del siglo XVI, las aldeas han empezado a entregar tierras para viñas ${ }^{14}$. El concejo de Mengabril recoge esta atribución, contestada por

\footnotetext{
${ }^{7}$ Para una adecuada compresión de esta unidad espacial y su evolución, $c f$. J. Clemente, Pautas de estructuración y fosilización, pp. 180-185.

${ }^{8}$ ACG, leg. 31, $\mathrm{n}^{\circ}$ 1, f. 41r. Los testigos hablan de un tiro, tiro y medio, y dos tiros de ballesta: ACG, leg. 31, no 1, ff. 247r, 254v y 264r.

${ }^{9}$ ACG, leg. $31, n^{\circ} 1$, f. 430r.

${ }^{10}$ ACG, leg. 31, no 1 , ff. 246v y 252 r.

${ }^{11}$ ACG, leg. 31, no 1 , ff. 280v y 282r.

${ }^{12}$ ACG, leg. 31, no 1 , ff. 286v-287r.

${ }^{13}$ AGS-CR, leg. 230, exp. 2-1, f. 110r.

${ }^{14}$ AGS-CR, leg. 140, exp. 2, ff. 109r y $118 \mathrm{v}$
} 
Medellín, en sus ordenanzas ${ }^{15}$. La villa también concede numerosas solares y $\operatorname{cercas}^{16}$. Todo esto produce cambios muy importantes en el paisaje y en la dedicación productiva de los ejidos.

Ya hemos mencionado la relación entre el ejido y la ganadería vecinal. Es posible que los ejidos aldeanos estuvieran muy vinculados al mantenimiento de los cerdos. Según Pedro Martín Peinado (Guareña), como ya indicamos, se destinaban para los puercos. En Medellín, sin embargo, a principios del siglo XVI el ejido se reserva para las bestias de serviçio de casa de los vezinos desta villa, prohibiéndose expresamente la entrada de otros ganados ningunos. También pueden entrar las bestias de los caminales $^{17}$. Probablemente, la realidad sería más compleja que la normativa expuesta en las ordenanzas de Medellín. El intento de apropiación condal de la cuesta del castillo de Medellín (1543 ó antes) nos presenta unas pautas de aprovechamiento algo distintas. Gaspar García, que echaba allí sus ganados mayores y menores, nos informa de que era aprovechada también por los carneros de la carnicería, los ganados serranos para que reposasen y las vacas acorraladas por mostrencas. Andrés Domínguez, de modo similar, nos indica como accedían todos los ganados que pasavan por las barcas e ovejas, e carneros o vacas, o otro qualquier ganado aunque fuesen forasteros. Cristóbal Serrano alude a bueyes e otras bestias e ganados ${ }^{18}$. Este espacio recogía todo tipo de ganado, incluido el forastero que transitoriamente estaba en la villa. Es muy posible que el mayor aprovechamiento se realizase por las bestias. Se alude de forma prácticamente exclusiva a bestias y asnos desorejados por los criados del conde. El 26 de mayo de 1541 se pregona la prohibición de introducir puercas en el ejido, sin que antes se haya aludido de forma específica a estos animales ${ }^{19}$.

Las restricciones en el aprovechamiento del ejido de Medellín quizás tengan que ver con la disponibilidad de la dehesilla/ejido de Camachos. Hacia 1540, cumple parcialmente funciones de dehesa boyal, junto a Remondo y el Prado. Se trata también de un espacio parcialmente cultivado, en un grado que no podemos precisar, al menos desde principios del siglo XVI. Por otro lado, es objeto de un aprovechamiento común con Mengabril. Finalmente, se arrienda también a ganaderos como dehesa de hierba.

${ }^{15}$ J. Clemente, Las ordenanzas de Mengabril, p. 604.

${ }^{16}$ El concejo de Medellín concedió once y trece solares en las anualidades de 1540-1541 y 1542-1543 en distintos núcleos de la tierra (AGS-CR, leg. 140, exp. 2-II, ff. 183v-197v y 213r-226v)

${ }^{17}$ ACG, leg. 31, no 1, f. 76r.

${ }^{18}$ AGS-CR, leg. 230, exp. 2-1, ff. 33r-35r.

${ }^{19}$ AGS-CR, leg. 140, exp. 2-II, f. 190v. 


\subsection{Dehesas boyales}

La dehesa boyal como espacio pecuario presenta un perfil particular. Se reserva a los animales de la labranza y mantiene una íntima relación con la coyuntura demográfica y agraria. Inexistentes hasta el siglo XIII, se convierten en una realidad generalizada en el periodo bajomedieval y moderno indicando, sin duda, la creciente presión sobre el espacio ${ }^{20}$. Cualquier aldea, por modesta que sea, cuenta con una dehesa boyal. El ejemplo de Martín Sancho, que se despuebla a mediados del siglo XV y que nunca debió superar los veinticinco vecinos, es ilustrativo. Tenía como dehesa boyal una espacio que se extendía entre la población y la sierra Luenga o Alcornocosa. En verano, se acotaba para los bueyes parte de la Sierra Acebuchosa, junto a la sierra de Enfrente o Remondo ${ }^{21}$.

El mantenimiento de los bueyes y en su caso de otros animales de labor ${ }^{22}$ es, sin duda, una de las mayores preocupaciones de las comunidades rurales. Por ello en caso de necesidad se toman las decisiones pertinentes. Hernando Alonso (Guareña) señala que los concejos pueden acotar libremente exidos e baldios para dehesa boyal. En este lugar, se ha actuado así desde quarenta e çinco años (c. 1455) a esta parte. Según Martín Albarrán, el ejido se suele acotar uno o dos meses para los bueyes. En Valdetorres el ejido puede acotarse entre marzo y San Miguel, llevándose luego los bueyes a la dehesa ${ }^{23}$. En julio de 1540, Alejo de la Cadena y Juan Moreno, jurados, piden que se les de un coto donde es costumbre para la boyada de la villa, asignándosele en el camino de Sevilla ${ }^{24}$. En Don Llorente, poco antes de mediados del siglo XVI, se acota su termino y restrojos adonde les pareçe que conviene para su boyada. En 1539, acotaron una parte de sus rastrojos ${ }^{25}$. Los ganados de Guareña, por las mismas fechas agostan en los rastrojos y dehesas del Gamero o Chaparral ante la insuficiencia de las dehesas disponibles ${ }^{26}$

Las dehesas boyales se ven condicionadas entre 1450 y 1550 por la coyuntura de crecimiento demográfico y agrario. Sin duda, el número de bueyes debió crecer de forma notoria e hizo insuficiente el espacio acotado. La villa nos ofrece un claro ejemplo. Medellín utilizaba como dehesa boyal la dehesa de Remondo y un espacio reducido llamado el Prado desde algún

\footnotetext{
${ }^{20}$ No se ha abordado satisfactoriamente su desarrollo: $c f$. J.M. Mangas, El régimen comunal agrario, pp. 161-163.

${ }^{21}$ J. Clemente, Martín Sancho (ss. XIV-XVI), p. 491.

${ }^{22}$ En Don Benito, a mediados del siglo XVI, se documentan también "bestias cavallares y mulares de yugo" (A. Bernal, Don Benito, p. 267).

${ }^{23}$ ACG, leg. 1950, no 6, ff. 128v-129r, 171r y 165 r.

${ }^{24}$ AGS-CR, leg. 140/2-II, f. 194r, y leg. 64, exp. 7/2, f. 30r.

${ }^{25}$ AGS-CR, leg. 230, exp. 2-1, f. 90v.

${ }^{26}$ ACG, leg. 479, no 3, f. 35r.
} 
momento indeterminado del siglo XV. La dehesa de Remondo se documenta en 1405 simplemente como heredat que disen de don Remondo, lo que parece indicar otra dedicación. En 1489, aparece ya junto al Prado como dehesa bo$\mathrm{yal}^{27}$. Cada vecino podía llevar a ella sus bueyes, una vaca de excusa por yunta y una yegua. El conde también introducía ganado a renta o de otro modo ${ }^{28}$. La dehesa de Remondo permitió el mantenimiento de los bueyes de la villa hasta el primer cuarto del siglo XVI.

En Valdetorres, antigua dehesa de los Mejía, la dehesa boyal se amplía en dos ocasiones en el último tercio del siglo XV, entre 1460-1470 y $1488-1496^{29}$. Esta temprana ampliación se debe a circunstancia muy locales que no podemos extrapolar.

La disponibilidad de dos dehesas boyales parece indicar en algunos casos la existencia de procesos de ampliación. Al margen de Valdetorres y Medellín, Guareña cuenta con la dehesas de Abajo y Chaparral; Don Benito, con una dehesa próxima a la localidad y la de Veguilla. Sólo Miajadas, entre los núcleos más poblados, cuenta con una sola dehesa boyal. Algunas de estas dehesas no parecen tener esta dedicación en fechas tempranas. La Veguilla es cedida por Fernando de Antequera entre 1393 y 1412 a Don Benito para que la puedan pastar con sus ganados o arrendar o fazer aquello que bien tovieren ${ }^{30}$.

En cualquier caso, las dehesas boyales parecen ajustadas a mediados del siglo XVI. Influyen dos realidades en esta situación: el crecimiento de la boyada y el arrendamiento parcial de los pastos. En 1550, Guareña solicita atravesar los ejidos de Valdetorres para poder abrevar en el río Guadámez por aver creçido mucho la vezindad y bueyes $^{31}$. Martín de Funes, alcalde mayor de Medellín, estima sobre las ordenanzas de Mengabril, que se deben confirmar las normativas sobre la dehesa boyal (cada vecino sólo puede introducir un buey holgón) por ser pequeña e andar cargada ${ }^{32}$. Un ejemplo claro de estos cambios lo ofrece la citada dehesa de Remondo. Hacia 1535, se va a regular de modo más restrictivo su aprovechamiento debido a que la villa tiene mucha falta de dehessa boyal. Se va a reservar, por acuerdo entre los propietarios, para el exclusivo aprovechamiento de los bueyes. El conde, sin embargo, contraviniendo la decisión sigue llevando su yeguada ${ }^{33}$.

${ }^{27}$ AHN, Osuna, carp. 63, $\mathrm{n}^{\circ} 2$.

28 “otrosy mandaron al dicho conde que en las dehesas de boyalaje de la dicha villa e su tierra no metiese ganado alguno forastero por dinero ni syn ello" (AGS-CR, leg. 519, exp. 7, f. $49 \mathrm{v})$.

${ }^{29}$ J. Clemente, Valdetorres, pp. 56-57.

${ }^{30}$ AGS-CR, leg. $128, n^{\circ} 11$, f. $17 \mathrm{v}$.

${ }^{31}$ ACG, leg. 479, $\mathrm{n}^{\circ} 3$, ff. 11r-11v.

${ }^{32} \mathrm{~J}$. Clemente, Las ordenanzas de Mengabril, p. 650.

${ }^{33}$ AGS-CR, leg. 230, exp. 3, ff. 24r-24v, 45r y 71v-72r. 


\subsection{Arriendo de pastos comunales}

Los comunales se van a convertir en una importante fuente de financiación para las aldeas, que no disponen de propiedades ni rentas importantes ${ }^{34}$. El acogimiento de ganado a renta en los comunales aldeanos es una realidad desde finales del siglo XV. La sentencia del juez Peralta (1500) alude a la posibilidad de que Valdetorres introdujese vacas y carneros de serranos e de otras personas en el coto nuevo de las Cabezas Luengas ${ }^{35}$. El procurador de María de Obando (nuera de Pedro Mejía), señala que los concejos de Rena y Valdetorres acogen en sus ejidos otros [ganados] por dineros para sus neçesidades ${ }^{36}$.

$\mathrm{El}$ acogimiento de ganado a renta parece haber adquirido una gran importancia en el segundo cuarto del siglo XVI. Según los oficiales de Miajadas de 1538-9, existía costumbre inmemorial de realizar estos acogimientos en las dehesas boyales, ejidos y cotos con el consentimiento de los propietarios de bueyes. Algunos vecinos sitúan el comienzo de esta costumbre treinta o quince años antes, es decir, entre 1510-1525 ${ }^{37}$.

En 1533, el alcalde mayor Hernando de Sosilla dispone, tras una denuncia previa, que Don Benito no acoja ningún ganado a renta en la dehesa boyal. Esta decisión se hace extensible a toda la jurisdicción. Las aldeas reclaman señalando la costumbre de acoger algunas reses vacunas en los exidos e dehesas boyales de los tales lugares con la aprobación vecinal. Al no disponer de otros propios, los ingresos generados evitaban realizar repartimientos de impuestos. Finalmente, los concejos de la tierra verán reconocido en 1537, en contra del parecer de la villa, su derecho a realizar acogimientos de reses en sus comunales con el consentimiento de la mayoría de los propietarios de bueyes ${ }^{38}$.

$\mathrm{El}$ acogimiento de ganado en los comunales aldeanos es una realidad generalizada en el siglo XVI. En 1539-1540, se acogieron en la dehesa de la Veguilla (Don Benito) dieciséis añojos de Nuño de Saavedra (Villanueva) y un número indeterminado de novillos ${ }^{39}$. Según Juan Fernández del Villar, Miajadas obtuvo en 1537-1538 cien mil maravedís de los acogimientos realizados en los ejidos. Juan García Cañamero, escribano de esta aldea en 1539-1540, estima en ochenta y cinco o noventa mil maravedís los ingresos por este con-

\footnotetext{
${ }^{34}$ No estamos ante una práctica excepcional: M. Diago, La aplicación en la Sierra soriana del derecho de posesión mesteño, pp. 66-69; J.M. Andrada, Los propios, comunes y baldíos de Mérida, pp. 52 y 59.

${ }^{35}$ ACG, leg. 1950, nº 6, f. 238r.

${ }^{36}$ AGS, Registro General del Sello, 1497-febrero, f. 292.

${ }^{37}$ AGS-CR, leg. 231, exp. 6, ff. 85v-86r, 88r y 89r.

${ }^{38}$ ACG, leg. 455, no 3, ff. 21r-22v y 25r.

${ }^{39}$ AGS-CR, leg. 231, exp. 9, f. 11r; AGS-CR, 230, exp. 2-1, f. 67r.
} 
cepto (ganados estranjeros y vecinales). Sólo pasaron ante él los acuerdos con estos últimos ${ }^{40}$ :

\begin{tabular}{|l|c|c|}
\hline \multicolumn{3}{|c|}{$\begin{array}{c}\text { Cuadro no 1 } \\
\text { Miajadas (1538-1539): } \\
\text { ganados acogidos en dehesas y ejidos }\end{array}$} \\
\hline Propietario & Especie & Mrs. \\
\hline Antón Hernández & - & 12.000 \\
\hline Gil Monte & ovejas & 28.000 \\
\hline Pedro Merino & Carneros & 7.750 \\
\hline Pedro Merino & - & 6.000 \\
\hline- & erales, novillos y vacas \\
de leche & 2.770 \\
\hline- & $\begin{array}{c}\text { novillos (20) y vacas } \\
\text { de leche (6) }\end{array}$ & 544 \\
\hline TOTAL & & $\mathbf{5 7 . 0 6 4}$ \\
\hline
\end{tabular}

Considerando el pago de un real por cada una de las seis vacas de leche citadas, el ingreso total supone la introducción en los comunales del equivalente de dos mil seiscientas vacas en idénticas condiciones o de casi trescientas vacas en las dehesas. Estamos ante entradas temporalmente muy localizadas. Se trata prácticamente del único ingreso reseñable de la hacienda local ${ }^{41}$. Estos datos debemos compararlos con los 107.877 maravedís que alcanzaron los ingresos de Don Benito en $1540^{42}$. Las necesidades de financiación van a incidir significativamente en la explotación de los comunales aldeanos.

\subsection{Los propios}

Los propios, término genérico que alude a todas las fuentes de ingreso de los concejos, designan en un sentido más estricto a los bienes raíces que no se destinan al aprovechamiento gratuito de los vecinos, sino que se ceden por el pago de una renta. La oposición entre propios y comunales es nítida y

${ }^{40}$ AGS-CR, leg. 231, exp. 6, ff. 39r-40v y 155r.

${ }^{41}$ Según el escribano Juan García Cañamero, sólo habría que añadir a esta fuente de financiación la renta y pena de las viñas $-2.025 \mathrm{mrs}$. - y los cotos y la renta de los panes -12 reales(AGS-CR, leg. 231, exp. 6).

${ }^{42}$ AGS-CR, leg. 231, exp. 9, f. 1v. 
clara. Sin embargo, no puede entenderse como una realidad estática. En Medellín, los propios pueden tener alguna servidumbre comunal y algunos comunales ser objeto de arriendos parciales que engordan los ingresos concejiles.

Los propios de Medellín susceptibles de aprovechamiento pecuario están formados por una serie de dehesas sujetas a servidumbres comunales. En el vaqueamiento de 1460 y en el listado de 1510 totalizan 1.840 vacas de hierba (Canchal, 1.100; Carrascal, 500; Matilla 200; Camachos, 40), algo menos del $4 \%$ de la capacidad ganadera del espacio adehesado ${ }^{43}$.

Estas dehesas de propios tienen un régimen especial de explotación. Los vecinos pueden llevar allí sus ganados durante todo el año. Esto parece mantenerse a lo largo de todo el periodo estudiado. Martín Arias, vecino de Valdetorres, nos informa de que hacia 1492 su padre llevaba sus puercos al Canchal sin cortapisa alguna ${ }^{44}$. En relación con las cuentas de 1538-9, el regidor Diego García Altamirano señala como la Matilla tiene que arrendarse por un precio inferior a su capacidad ganadera porque, en su calidad de propio, los puercos y otros ganados pueden andar en ella todo el año $0^{45}$.

Los rendimientos económicos de estos propios eran, por tanto, moderados. Junto a este bajo rendimiento deberíamos añadir la problemática inherente a su carácter concejil. En este sentido, debemos considerar las acusaciones sobre arriendos que benefician a determinadas personas o los intentos de apropiación del conde, que se inscriben en sus deseos de tener un control estricto sobre el concejo.

\begin{tabular}{|l|c|c|c|}
\hline \multicolumn{4}{|c|}{ Cuadro $^{\mathbf{0}}$ 2 } \\
Rendimientos de las dehesas de propios \\
\hline Dehesa & Año & Renta (mrs.) & Mrs./vaca-hierba \\
\hline $\begin{array}{l}\text { Canchal, Carrascal y } \\
\text { Matilla }\end{array}$ & 1494 & $66.666^{1}$ & 37,04 \\
\hline Canchal y Carrascal & 1494 & $100.000^{2}$ & 58,82 \\
\hline Canchal y Carrascal & $1498-1499$ & $130.000^{3}$ & 81,25 \\
\hline
\end{tabular}

${ }^{43}$ AMG, leg. 131, doc. 65, y cód. 129, 209v-211r. Estos propios son comparables a los de Mérida o Cáceres, aunque claramente inferiores a los de Trujillo: $\mathrm{M}^{\mathrm{a}} \mathrm{A}$. Sánchez Rubio, El concejo de Trujillo, pp. 234-238; J.M. Andrada, Los propios, comunes y baldios de Mérida, pp. 38-39, 40 y 50; $\mathrm{M}^{\mathrm{a} D}$. García Oliva, Organización económica y social, pp. 157-167 y 274-275. Una estimación genérica de los ingresos de Medellín en AGS-CR, leg. 140, exp. 2, ff. $5 \mathrm{r}-7 \mathrm{v}$ y $214 \mathrm{v}-216 \mathrm{v}$.

${ }^{44}$ ACG, caja $1353, n^{\circ} 9-4$, f. 150v.

${ }^{45}$ AGS-CR, leg. 140, exp. 2, f. 306v. 


\begin{tabular}{|c|c|c|c|}
\hline \multirow{2}{*}{ Canchal } & $1505-1506$ & 81.865 & 74,42 \\
\hline & $1538-1543$ & 106.37 & 96,70 \\
\hline \multirow{3}{*}{ Matilla } & $1538-1539$ & 29.375 & 146,87 \\
\hline & $1539-1541$ & 29.000 & 145 \\
\hline & $1541-1543$ & 26.000 & 130 \\
\hline \multirow{2}{*}{ Carrascal } & $1538-1539$ & 26.375 & 52,75 \\
\hline & $1539-1543$ & 30.375 & 60,75 \\
\hline \multirow{5}{*}{ Camachos } & $1538-1539$ & $10.200^{4}$ & 255 \\
\hline & $1539-1540$ & 10.000 & 250 \\
\hline & $1540-1541$ & 4.500 & 112,5 \\
\hline & $1541-1542$ & 11.000 & 275 \\
\hline & $1542-1543$ & 15.000 & 375 \\
\hline${ }^{1}$ sentencia & \multicolumn{3}{|c|}{${ }^{2}$ estimación del conde $\quad{ }^{3}$ estimación del concejo } \\
\hline
\end{tabular}

Estos propios proporcionan a Medellín unos ingresos muy importantes. A finales del siglo XV, para unos ingresos totales estimados de unos doscientos mil maravedís, las dehesas de Canchal y Carrascal podían rentar, según cálculos del representante del conde, cien mil maravedís ${ }^{46}$. Poco antes de mediados del siglo XVI, los propios proporcionan unos ciento setenta y cinco mil maravedís, casi la mitad de los ingresos concejiles. La renta del Canchal cuando menos dobla cualquier otro ingreso municipal. Pese a ello, no parece que se saque todo el rendimiento posible. En la detallada investigación que se realiza sobre las cuentas de Medellín de 1537-1543, Hernán López de Ávalos acusa al concejo de entregar las dehesas de propios por menos dinero de su valor. Para el bienio 1541-1543, considera que se hubieran podido recaudar las siguientes cantidades: Canchal, ciento cincuenta mil maravedís; Carrascal, sesenta-ochenta mil maravedís y dos toros; La Matilla, cincuenta mil; dehesilla de Camachos (15411542), doce mil maravedís ${ }^{47}$. Hernán Pérez de Ávalos está pensando en un rendimiento en torno a los doscientos noventa mil maravedís (aproximadamente, $156 \mathrm{mrs} . / \mathrm{vaca}$-hierba). Según él, la cantidad defraudada se acercaría a los cien mil maravedís. Los testigos que presenta realizan valoraciones más modestas. Melchor Rodríguez (Magacela), estima un valor de cuarenta mil maravedís para

${ }^{46}$ Representantes de la villa y tierra de Medellín calculan en 1494 que "la dicha villa tenia de proprios fasia doçientas mill mrs." (AGS-CR, leg. 39, n 5, f. 30v).

${ }^{47}$ AGS-CR, leg. 140, exp. 2-IV, f. 54v, y exp. 2, f. 28r. 
la dehesa de Carrascal y 37.500 para la Matilla en $1542-1543^{48}$. Algunas sentencias correspondientes a los diversos años investigados afectan a las dehesas de propios. En 1538-9, Francisco López arrendó la dehesa de Carrascal. Este personaje es deudo del conde, procurador el año anterior, regidor y elector ${ }^{49}$. También disfrutará esta dehesa otros años. La pérdida de ingresos está relacionado, al menos en parte, con una corrupción municipal que no puede entenderse al margen de los intentos de mediatización y control condal.

Junto a la pérdida de ingresos, otro riesgo aún mayor es el control condal de los propios. Los Portocarrero, señores de Medellín desde 1449, van a intentar arruinar un modelo concejil heredado que hemos definido como realengo. Junto a la apropiación de despoblados y su conversión en dehesas (Don Salvador, Martín Sancho), intentarán controlar los propios y adueñarse de sus rentas. Entre 1488, aproximadamente, y 1498, el conde de Medellín tiene ocupados el Canchal, el Carrascal y la Matilla ${ }^{50}$. Una sentencia de 1494 le condena a pagar doscientos mil maravedís, cantidad muy moderada, por los ingresos de tres años. Este control de las dehesas de propios quizás esté muy relacionado con el intento frustrado del concejo y de Juan Núñez de Prado, cabeza del linaje Mejía, de llegar a un acuerdo con el conde. El procurador condal señala que los oficiales concejiles se las habían cedido para socorro de las neçesydades que el dicho su parte tenia porque el tenia enpeñadas sus rentas para conplir con la condesa (su madre Beatriz Pacheco) ${ }^{51}$.

No sabemos en que momento el concejo de Medellín volvió a controlar las dehesas de propios. En 1505, el concejo cede nuevamente al conde por tres años la dehesa del Canchal como ayuda para su matrimonio. El concejo recibe la renta de los paños, cesión meramente formal puesto que formaba parte de los derechos concejiles. El conde, además, mantiene el control sobre esta renta. Para el bachiller Sanabria, las mazmorras constituían una amenaza suficientemente disuasoria ${ }^{52}$.

En 1509, el concejo de Medellín cede la renta de la dehesa del Carrascal a los frailes franciscanos para que construyan un monasterio en la localidad. Esta donación, según Juan de Robles, procurador de la villa, no tenía justificación alguna puesto que obligaba a realizar derramas e repartimientos para subvenir a las necesidades municipales. Parece que dicha donación no

${ }^{48}$ AGS-CR, leg. 140, exp. 2-IV, f. 73r.

${ }^{49}$ AGS-CR, leg. 140, exp. 2, ff. 409v-410r.

${ }^{50}$ El conde no debió mantener su control mucho más tiempo. A esta situación parece referirse Fernando de Robles, vecino de Medellín, cuando señala que se apropió de la dehesa del Canchal siete u ocho años (AGS-CR, leg. 39, exp. 5, f. 52r).

${ }^{51}$ AGS-CR, leg. 39, exp. 5, f. 32v, y leg. 519, exp. 7, f. 49v; AGS-CCP, leg. 11, no 394-11.

${ }^{52}$ AGS-CR, leg. $39, n^{\circ}$ 5, f. 11r, 17 r y $54 \mathrm{r}$ 
era ajena a la voluntad condal y se vio facilitada por oficiales concejiles elegidos irregularmente ${ }^{53}$. Todo parece indicar que el conde ha mediatizado la decisión y que intenta, a costa del concejo, realizar una donación a los frailes franciscanos.

A partir de 1512, el conde de Medellín recibe veinte mil maravedís sobre la dehesa del Canchal para compensar la disminución que puedan sufrir las alcabalas por la concesión de un mercado franco. Hacia 1542, esta cantidad de dinero aparece situada en la Matilla ${ }^{54}$.

En 1534, el conde incomoda durante la sementera la explotación de la dehesa del Canchal que tenia arrendada el concejo de Miajadas. Finalmente, se sembró poco y a destiempo ${ }^{55}$. No parece que en este caso la finalidad sea tanto la apropiación como la actuación contra un concejo aldeano.

En 1539, el conde controla la Matilla, que ha cedido en arriendo a Guadalupe, posiblemente sin contrato escrito alguno. En 1542, el concejo de Medellín y Guadalupe formalizan el arriendo de La Matilla por ocho años desde San Miguel de 1541 por veintiséis mil maravedís y un toro (ó 2.500 maravedís) cada año $0^{56}$. El dinero del acuerdo, que se paga por adelantado, se destina al conde para ayuda de las lanças que Su Magestad le manda que enbie $e^{57}$.

La interferencia condal sobre la explotación de los propios es recurrente. Constituyen una fuente de ingresos muy saneada y deseada. Por otro lado, miembros cualificados del poder local acceden a su explotación en condiciones con seguridad favorables.

\section{LAS DEHESAS}

Las dehesas constituyen, como hemos puesto de manifiesto, un espacio omnipresente y estable en la tierra de Medellín. A lo largo del periodo medieval, se va configurando una explotación rentista con la cesión a propietarios ganaderos, trashumantes o no. Este perfil, con todo, no agota su aprovechamiento. En su origen, sus propietarios sólo pudieron acotar el pasto. Las dehesas presentan otros recursos como el monte. Desde este punto de partida, a finales de la Edad Media se presentan situaciones diferenciadas vinculadas a la dinámica sociopolítica de las diversas jurisdicciones. En el caso de Medellín, junto al pasto de las dehesas, objeto de apropiación y/o explotación

${ }^{53}$ AGS-CCP, leg. 11, $\mathrm{n}^{\mathrm{o}} 385$.

${ }^{54}$ AGS-CR, leg. 230, exp. 1, f. 125v, y exp. 3, f. 34v.

${ }^{55}$ AGS-CR, leg. 87, exp. 14.

${ }^{56}$ AGS-CR, leg. 230, exp. 1, f. 40v.

${ }^{57}$ AGS-CR, leg. 140, exp. 2, ff. 20r-21v. 
privadas, aparecen otros recursos de notoria importancia económica sujetos al aprovechamiento vecinal. Concurren, por tanto, en las dehesas derechos privados y vecinales. Esto marca una diferencia notoria entre las dehesas con o sin monte, dado que las últimas se verán libres en gran medida de las servidumbres comunales de las primeras.

\subsection{Estructura y difusión espacial}

La tierra de Medellín es un espacio fundamentalmente pascícola. Las dehesas y los propios adehesados, como hemos indicado, ocupan la mayor parte del territorio ${ }^{58}$. Los espacios de pastos sólo pierden importancia alrededor de algunas aldeas (Valdetorres-Guareña, la primera una dehesa hasta la primera mitad del siglo XV; Don Benito-Don Llorente; en menor medida, Miajadas). No sucede así con la villa, que se vio rodeada de dehesas o propios adehesados, aspecto que no debemos olvidar al explicar su paulatina y relativa modestia demográfica desde la primera mitad del siglo XVI.

El vaqueamiento de las dehesas realizado en 1460, que recoge un acuerdo entre el conde Rodrigo Portocarrero y ganaderos mesteños, y el listado de 1510, que añade algunas dehesas no incluidas en el primer documento, nos permiten valorar la capacidad ganadera de la tierra de Medellín ${ }^{59}$. Las dehesas tendrían una capacidad cercana a las veintiséis mil vacas de hierba.

Más importante aún que esta cantidad, tremendamente elevada, es el reparto geográfico de las dehesas, que nos permite ver como colmatan gran parte de la jurisdicción ( $c f$. mapa 2$)^{60}$. Las dehesas aparecen frecuentemente rodeadas por otras dehesas o espacios ganaderos. Algunos casos nos permiten verlo con claridad. El despoblado adehesado de Martín Sancho está rodeado por las dehesas de Remondo, Rincón, Patilla y Menga Gil. Los ejidos y baldíos del Villar de Rena aparecen siempre limitados por distintas dehesas y la Matilla, propio de Medellín ( $c f$. mapa 1$)^{61}$. El espacio adehesado y pascícola

\footnotetext{
${ }^{58}$ Estamos ante una realidad ampliamente difundida en Extremadura y en general en la submeseta meridional. Citaremos sólo algunos ejemplos significativos: V. Clement, Spanish wood pasture, p. 69, fig. 1; J. Clemente, La tierra de Medellín (1234-c. 1450), pp. 49-68; D. Rodríguez, La Orden de Santiago en Extremadura, pp. 251-252; M. Diago, El acceso a las dehesas de La Serena, pp. 60-61; M J. Lop, Un ejemplo del proceso señorializador extremeño, p. 224 y nota 70;. J. López-Salazar, Las dehesas de la Orden de Calatrava, p. 270.

${ }_{59} \mathrm{~J}$. Clemente, El vaqueamiento de las dehesas de Medellín, pp. 137-146.

${ }^{60}$ Sólo disponemos de una mapa equiparable aunque incompleto para Cáceres: $M^{a} D$. García, Organización económica y social, p. 284.

${ }^{61}$ ACG, leg. 1083, no 7, f. 5r; J. Clemente, El régimen agrario de Villar de Rena (en prensa).
} 
presenta una continuidad por debajo de la curva de nivel trescientos. En la zona sur de la jurisdicción, con modestos relieves, las dehesas ceden el dominio a la vegetación natural. En las rozas documentadas tardíamente se alude de forma reiterada a los montes bravos ${ }^{62}$. Las zonas de pastos, por tanto, se reparten por toda la tierra de Medellín con algunos vacíos en la proximidad de algunas aldeas y sobre todo por encima de los trescientos metros.

Las dehesas se presentan como realidades dinámicas que permiten fenómenos de absorción y división. La Refierza y Matamudiona, por ejemplo, aparecen formando una unidad a finales del siglo XIV. A mediados del siglo XVI y desde un momento que no podemos precisar, se han integrado en la dehesa de la Vega, con una capacidad conjunta de ochocientas vacas/hierba ${ }^{63}$.

La división parece un fenómeno más frecuente que la absorción. La propiedad de las dehesas de modo creciente se presenta fragmentada. Algunas están controladas en su totalidad por nobles, miembros cualificados de la oligarquía local o el monasterio de Guadalupe, pero muchas están compartidas por distintos propietarios como consecuencia de las divisiones hereditarias. La posesión de una parte $(1 / 2,1 / 4$, etc.) dará paso en el siglo XV a los maravedís $o$ vacas de hierba ${ }^{64}$. El arrendamiento independiente de partes de una dehesa no debió ser infrecuente. En Medellín, parece imponerse esta costumbre ${ }^{65}$, lo que sin duda abrió el camino a la fragmentación. Por ello se alude a mitades, cuartos, sexmos u ochavos como unidades que funcionan de modo autónomo. Es sintomático sobre el particular la situación del ochavo de la dehesa de Peñalobar de María y Mencía de Esquivel en 1539. Este ochavo pertenecía a las dos hermanas, lo que parece indicar una unidad indivisa segregada del resto de la dehesa. La primera arrendó en septiembre de 1539 su parte a García de Porras. La segunda tenía arrendada la suya a vecinos de Hoyocasero. García de Porras introdujo sus vacas en este ochavo (unas doscientas vacas para un terreno de algo menos de cuarenta y cuatro vacas/hierba), pese a ser requerido para que no las metiesen hasta que se partiese la tierra ${ }^{66}$. En el caso de Peñalobar parece cumplirse la normativa dominante en Medellín. Cada hermana

${ }^{62}$ ACG, leg. 1950, nº 6, ff. 182r-183v; AGS-CR, leg. 140, exp. 2-II, ff. 173r-226v.

${ }^{63} \mathrm{M}^{\mathrm{a}} \mathrm{F}$. Cerro, Documentación, docs. 149 y 150; AHN, Clero, carp. 397, n ${ }^{\circ} 11$; en 1553, las dehesas de Matamudiona (que absorbe la Refierza) y Vega "es aora todo uno, y se llama todo la Vega y esta todo junto" (AHN, cód. 111, f. 337).

${ }_{64}$ J. Clemente, La tierra de Medellín (1234-c. 1450), pp. 66-68; MD. García, Orígenes y expansión de la dehesa, pp. 94-95.

${ }^{65}$ AGS-CR, leg. 231, $n^{\circ}$ 4-II, f. 33: “qualquiera persona que tiene parte en qualquiera dehesa deste condado, ora sea poca o mucha la parte, que tienen derecho e posesyon de arrendar cada uno la parte que tuviere, e en qualquier dehesa, e ansy an hecho e hazen en este condado de Medellín e es ansy huso e costunbre husada e guardada syn ninguna contradisçion del dicho tienpo ynmemorial a esta parte".

${ }^{66}$ AGS-CR, leg. 231, $\mathrm{n}^{\circ}$ 4-II, especialmente ff. 1v, 10v y 22v. 
ha arrendado independientemente su medio ochavo antes de su deslinde y separación.

En algún caso nos consta la indivisión. Hacia 1540, la dehesa del Rinconcillo está toda junta arrendada ${ }^{67}$. La situación contraria se documenta más frecuentemente. La dehesa del Palazuelo de los Alvarados se encuentra a finales del siglo XV por yndiviso e por parte. El tercio que había pertenecido a Cecilia Vázquez formaba una unidad separada del resto de la dehesa. Alonso Fernández Portocarrero y su mujer María de Sotomayor a finales del siglo XV y principios del XVI parecen arrendar de forma independiente su parte en la dehesa del Guijo. En 1514, se realiza una separación de las partes que corresponden al monasterio de Guadalupe y a la viuda de Juan de Chaves, destacado miembro de la oligarquía trujillana ${ }^{68}$. También se encuentran separados desde un momento indeterminado, posterior a $1457, \operatorname{los} 3 / 4$ del monasterio de Guadalupe y el cuarto restante en la dehesa de Arroyo de las Puercas ${ }^{69}$. La dehesa de Cuadrado a sido partida de suelo e propiedad hasta abra dos años $(1538)^{70}$. Ya hemos mencionado el ejemplo de la dehesa de Peñalobar. El ochavo de las hermanas María y Mencía de Esquivel estaba separado del resto de la dehesa. En 1539, Juan de Aponte tenía arrendada una parte no precisada de la dehesa de Peñalobar a algunos vecinos de Don Benito ${ }^{71}$

La situación de la dehesa de Valverde (novecientas vacas/hierba), la conocemos con cierta precisión. La mitad de la dehesa se había dividido seguramente hacia finales del tercer cuarto del siglo $\mathrm{XV}$ en tres partes o sexmos que pertenecieron a Elvira Álvarez de Miranda, los Becerra e Isabel de Mendoza $^{72}$. La otra mitad correspondía a Catalina Mejía. Es posible que ambas mitades estuvieran divididas desde mucho antes. En 1426, Elvira Álvarez de Sotomayor dona aparentemente la dehesa de Valverde, sin que se precise que se trata sólo de la mitad, a María Sánchez de Sandoval. Esto sólo se explica si las dos partes estaban separadas. Catalina Mejía legó su participación en esta dehesa a sus hijos Luis de Alvarado y Juana Mejía. Los correspondientes cuartos estaban divididos en las últimas décadas del siglo XV. El de Juana Mejía

${ }^{67}$ AMG, cód. 72, ff. 124v, 128r y 132v.

${ }_{68}^{6}$ AMG, leg. 100, nºs 38 y 58; ACG, leg. 577, nº 24, f. 1 r.

${ }^{69}$ La parte del monasterio de Guadalupe tiene entre otros linderos "el otro quarto" (AMG, cód. 129, f. 75r). En 1457, "rynde toda ella quatro mill maravedis de los quales viene a la parte del monesterio tres mill maravedis", lo que nos hace pensar que formaba una unidad (AMG, leg. $79, \mathrm{n}^{\circ} 13$, f. 1r).

${ }^{70}$ AGS-CR, leg. 231, exp. 10, ff. 45r y 64r.

${ }^{71}$ AGS-CR, leg. 140/2-II, f. 177v.

72 "la mitad de toda la dicha dehesa se fiço tres partes y el dicho sexmo que asi cupo a la dicha Elvira Alvarez, nuestra madre, linda de la una parte con el otro sexmo de Becerras y con otro sexmo de Ysavel de Mendoza" (AMG, cód. 72, f. 272r). 
estaba a finales de este siglo pro indiviso e partir $^{73}$. Hacia 1500, la dehesa de Valverde estaba dividida por tanto en cinco partes: una mitad se dividía en tres sexmos y la otra mitad en dos cuartos.

El monasterio de Guadalupe va a adquirir participaciones en la dehesa de Valverde entre 1495-1501 y 1533-1541 en los distintos cuartos y sexmos hasta controlar la mayor parte. En 1549, tras comprar a Álvaro de Osorio cincuenta vacas de hierba, poseía algo menos de seiscientas vacas de hierba (2/3). No sabemos con precisión como afectaron estas compras a la división física de la dehesa. En el año señalado, el vendedor indica que su parte esta proindivissa y junta con dehesa del dicho monasterio de Guadalupe y con otros herederos ${ }^{74}$. Es posible que se hubiera llegado a algún tipo de concentración que respondiera a la nueva situación.

\subsection{La explotación del monte: el verde}

La monarquía sólo permitió el acotamiento legal del pasto de las dehesas. Pese a ello, los propietarios conseguirán monopolizar en algunas jurisdicciones el aprovechamiento de todos los recursos ${ }^{75}$. En Medellín, la caza, la madera o la bellota tienen un carácter comunal ${ }^{76}$. Las dehesas constituyen un componente fundamental de los aprovechamientos vecinales.

La renta del verde, que forma parte de los propios del concejo, se recauda mayoritariamente sobre las dehesas. Grava el aprovechamiento del bosque por parte de personas ajenas a la jurisdicción ${ }^{77}$. Esta renta se sitúa detrás, aunque a mucha distancia, de las dehesas de propios, que proporcionan los ingresos más crecidos. En 1538-1543, suponen entre cincuenta y dos y treinta y dos mil maravedís. El concejo de Medellín le asigna una gran antigüedad, que habría que situar como poco a finales del siglo XIV. No es probable su existencia mucho más allá y quizás este límite temporal sea excesivo ${ }^{78}$.

${ }^{73}$ AMG, cód. 126 bis, f. 80v. Igualmente, AMG, cód. 72, ff. 282r y 279r.

${ }^{74}$ AMG, cód. 72, f. 320r.

75 J. Clemente, La organización del espacio agropecuario, pp. 73-74. Resultaría muy conveniente una encuesta sistemática sobre la materia. Sobre la existencia y la probable eliminación en algunos casos de derechos comunales en grandes explotaciones ganaderas y agrarias, contamos con algunos estudios interesantes: Maj. Suárez, La villa de Talavera, pp. 248-255, y M.A. Ladero, Donadios en Sevilla, pp. 33-41.

${ }^{76}$ Una situación similar parece documentarse en Mérida, no así en Badajoz, pese a conservarse algunos derechos comunales sobre las dehesas: J.M. Andrada, Los propios, comunes y baldíos de Mérida, pp. 59 y 65; J. Fernández, Badajoz y su tierra, p. 125.

${ }^{77}$ Estamos ante una realidad que alcanza una gran difusión: P. García, J.M ${ }^{\text {a }}$ Sánchez, Arbitrios locales, p. 403.

${ }^{78}$ AGS-CR, leg. 64, exp. 7/5, f. 12 
La renta del verde tiene un doble perfil. Por un lado, hay un gravamen regular por dehesa o fuego de pastores, lo que en muchos casos vendría a ser lo mismo ${ }^{79}$; por otro, integra las penas originadas por la explotación del bosque. No sabemos desde cuando se ha impuesto el pago de doce maravedís por dehesa. Diego del Castillo (Escurial -Trujillo) pese a remontar su memoria hasta 1475 aproximadamente, no lo recuerda. Juan López Cano (Lozoya -Segovia), sitúa de poco tienpo aca el pago de veinticuatro maravedís. Este incremento debió ser una moderada respuesta a la devaluación del maravedí y el incremento de los precios ${ }^{80}$. En todo caso, esta renta debe hacernos reflexionar sobre los teóricos privilegios de la Mesta y reducirlos a sus justos límites ${ }^{81}$.

El acuerdo establecido en 1489 entre Medellín y la Mesta nos aclara el uso que los pastores trashumantes, y en general los ganaderos, podían hacer de los recursos forestales. Según este acuerdo, los mesteños pueden cortar leña verde y seca y retama... para sus hatos, para sus fuegos e bardas y estacas, para sus corrales e para cozer pan e guisar de comer, y para lo otro neçesario. Asimismo, pueden cortar madera para fazer un corral cada año a cada rebaño. Se prohíbe la tala de árboles. Finalmente, el canon fijo del verde se sitúa nuevamente como solian pagar en doce maravedís ${ }^{82}$.

La cantidad fija que se paga por el verde no parece excesivamente significativa. Con el acuerdo de 1489, la recaudación por este concepto se situaría en algunos centenares de maravedís. El monto fundamental debía provenir de una doble vía: las penas por las infracciones y las cantidades devengadas por acuerdos con los arrendadores. Ambos aspectos debían estar íntimamente relacionados. Los acuerdos serían tanto más aconsejables cuanto más rigurosos fueran los arrendadores en la vigilancia y recaudación de penas. Las penas han debido tener un peso creciente. En las décadas de 1470 y 1480 , parecen importantes. Los ganaderos mesteños las ven como un peligro real. Las penas impuestas son elevadas: quinientos maravedís por cortar ramón, mil quinientos maravedís por una rama de alcornoque, o hasta siete mil maravedís (rebajados posteriormente a dos mil quinientos) por unas ramas que debieron ser numerosas ${ }^{83}$.

${ }^{79}$ AGS-CR, leg. 64, exp. 7/5, f. 12 r y preg. 9, testigo 6.

${ }^{80}$ AGS-CR, leg. 64, exp. 7/7, preg. 14, testigo 25, y exp. 7/6, preg. 10, testigo 43. Sobre la devaluación monetaria y la subida de precios: A. Mackay, Las alteraciones monetarias, pp. 238-239 y 245-248; R. Izquierdo, Precios y salarios en Toledo, pp. 42-44; C. Luis, La comunidad de villa y tierra de Piedrahíta, pp. 414-417 y 420.

${ }^{81}$ En este sentido, F. Marín, La configuración institucional, pp. 67-92, considera los privilegios de los Reyes Católicos una manifestación de la lucha defensiva de la Mesta para obtener mejores condiciones en las negociaciones con los agentes locales

${ }^{82}$ AGS-CR, leg. 64, exp. 7/2, ff. 29v-30r.

${ }^{83}$ AGS-CR, leg. 64, exp. 7/7, pregunta 15, testigos 5, 8 y 11. 
El nivel de estas penas produjo la generalización de los conciertos con los arrendadores. En 1543, el procurador Melchor Rodríguez estima que venden los montes con consecuencias negativas. Sitúa el valor real de la renta del verde en cincuenta mil maravedís ${ }^{84}$. Los acuerdos para el aprovechamiento del bosque también se documentan en el último cuarto del siglo XV. Juan López Cano, vecino de Lozoya del Valle (Segovia), señala que cada ganadero se yguala con los montarases e arrendadores del verde como mejor puede. Juan Bernaldo confirma la existencia de estos acuerdos para el periodo 1474-148985. La elevación de las penas, derivadas del celo de los arrendadores y del cambio que se está produciendo en relación con el bosque desde la segunda mitad del siglo $\mathrm{XV}^{86}$, ha inducido a los ganaderos, especialmente trashumantes y riberiegos, a establecer acuerdos con los arrendadores del verde para poder realizar un aprovechamiento conveniente del bosque. Penas y avenencias han generado los mayores ingresos frente a un cano fijo que ha debido adquirir de modo creciente, sobre todo a partir del acuerdo de 1489, un carácter marginal. Queda abierta la cuestión de si estos acuerdos han incidido de modo negativo en la adecuada conservación de la riqueza forestal.

El aprovechamiento del bosque por forasteros es, en todo caso, un hecho potencialmente conflictivo. En 1506, en un contexto de dificultades que también afecta a los recursos pecuarios, los daños infligidos por los mesteños para el ramoneo del ganado en dehesas y montes se estiman en más de dos cuentos de maravedís ${ }^{87}$.

El bosque también fue materia de conflicto con el monasterio de Guadalupe, institución de gran importancia económica en el ámbito medellinense. La sentencia del licenciado Francisco de León en 1532 autoriza a sus pastores y criados a cortar leña para sus necesidades en sus dehesas, aunque les prohíbe cortar encina, alcornoque o fresno ${ }^{88}$. En una concordia algo posterior, de diciembre de 1533 , se permite al monasterio cortar leña e madera libremente en todos los montes de la dicha villa e su tierra guardando las ordenanzas de la villa ${ }^{89}$.

${ }^{84}$ AGS-CR, leg. 140, exp. 2, f. 193r.

${ }^{85}$ AGS-CR, leg. 64, exp. 7/7, preg. 14, testigo 25, y preg. 15, testigo 24.

${ }^{86}$ J. Clemente, La evolución del medio natural, pp. 23-26.

${ }^{87}$ AGS-CCP, leg. 11, no 394-5.

${ }^{88}$ ACG, caja 1353, no 9-3, f. 127v.

${ }^{89}$ AMG, cód. 72, f. 481r. 


\subsection{La montanera}

La bellota, recurso de fundamental importancia ${ }^{90}$, está sujeta al aprovechamiento vecinal. Hacia mediados del siglo XV se ha ido fijado lo que parece una nueva forma de explotación, muy vinculada sin duda al desarrollo de la ganadería porcina ${ }^{91}$. Alonso Martín, vecino de Miajadas (1538-1539), habla de una hordenança antigua que vetaba el acceso de los puercos a la bellota hasta el desacoto (Todos los Santos) ${ }^{92}$. No tenemos ninguna información adicional sobre esta costumbre o su vigencia temporal.

La explotación de la montanera se ajusta durante el periodo que estudiamos a las siguientes pautas. Los cerdos podían acceder a las dehesas cavalleriles entre San Miguel (29 de septiembre) y San Andrés (29 de noviembre) y a los terrenos concejiles a lo largo de todo el año ${ }^{93}$. Entre San Miguel y Todos los Santos, los puercos comen la bellota caída. Este último día, con la bellota cahedera $^{94}$, se desacota. Durante los tres días siguientes, la recogen los vecinos, que seguramente obtienen ahora gran parte de la producción. Durante el desacoto, los cerdos abandonan las dehesas. En 1505, los concejos aldeanos muestran su temor de que se queden sin espacio disponible. Señalan que la bellota se desacotaba hasta entonces en dos partes, las adehueras y los montes de dentro (¿costumbre antigua?). La villa responde que la bellota se desacota toda junta y que durante el desacoto se señalan algunos montes para los cerdos $^{95}$. En 1542, se fija el desacoto de la bellota entre el 2 y el 4 de noviembre. Se reserva para los cerdos la Sierra de Rena, las Cabezuelas, la Cañada Cortidera y las Cañadas y Sierra de Yelves. El resto del mes de noviembre, la bellota se reserva para estos animales y puede varearse sin pena alguna ${ }^{96}$. Tras

${ }^{90}$ En la dehesa de Castilseras, en el maestrazgo calatravo, la bellota supuso el $19,41 \%$ y el $5,27 \%$ de los ingresos totales en 1562 y 1563 (J. López-Salazar Pérez, Las dehesas de la Orden de Calatrava, p. 277).

${ }^{91}$ El ganado porcino, desde la baja Edad Media, irá adquiriendo una importancia creciente en este aprovechamiento: M. Diago, Aprovechamiento de baldíos y comunales, p. 425; L.J. Coronas, La economía agraria, p. 321; J. Clemente, La explotación económica del Campo Arañuelo, pp. 267-268.

${ }^{92}$ AGS-CR, leg. 510, exp. 18, f. $17 \mathrm{r}$.

${ }^{93}$ AGS-CR, leg. 140, exp. 2, f. 110r.

${ }^{94}$ AGS-CCP, leg. 11, no 393-4, f. 1r.

${ }^{95}$ AGS-CR, leg. 140, exp. 2, ff. 111r-112r.

${ }^{96}$ Pedro Vázquez, vecino de Medellín: "de çinquenta años a esta parte [c. 1482-1532]... de San Miguel a San Andres en todas las dehesas del condado que tienen montes pueden traer puercos para que coman la bellota que se cayere, salvo tres dias despues de Todos Santos e que an de salir los puercos de los dichos montes para que los vesinos de la dicha villa de Medellyn e su tierra cojan la bellota, e pasados los dichos tres dias pueden varear la bellota a los puercos hasta Sant Andres; e que sabe que en el mes de San Miguel a Todos Santos ningun señor de dehesa ni que la tenga arrendada, si en ellas ay montes de bellotas, en el dicho tienpo no pueden 
el desacoto, la bellota debía ser escasa. Cerdos y vecinos realizan el aprovechamiento fundamental de este recurso que genera no pocos inconvenientes a los arrendatarios ${ }^{97}$.

Los derechos comunales sobre la montanera generan un problema que tendrá una larga evolución. Los arrendatarios y/o propietarios de las dehesas con monte, trashumantes, riberiegos y estantes, podían ser prendados durante su explotación. En 1517, un testigo indeterminado señala que había oído decir a onbres biejos ançianos referido a tienpo antiguo, que los vecinos que tenían dehesas arrendadas sacaban sus ganados entre San Miguel y Todos los Santos a los baldíos, mientras estaba acotada la bellota, para que no les matarán vacas y terneros, recurso que no estaba al alcance de mesteños o riberiegos. Posteriormente, volvían a introducirlos en las dehesas. García de Vargas, cuyo ganado pasta en Torre de Caños entre 1497-1499 aproximadamente, no sacó su ganado, sin que ello le produjese ningún contratiempo. Francisco González, vecino de Miajadas, también se refiere a un tienpo antiguo en el que se acostumbraba a llevar dosientos o tresientos maravedis de cada ato por lo que comian de la vellota en el tienpo que estava acotada e que no se matavan bacas ni terneras ${ }^{98}$.

Tardíamente se desarrolla la costumbre de matar una vaca y una ternera, $\mathrm{u}$ otros animales, por rebaño en las dehesas con monte durante la montanera. Esta práctica no se había desarrollado aún en la segunda mitad del siglo XV. Alonso Martín Collado, vaquero de varios vecinos de Collado de la Sierra, señala que hacia 1487-1482, en Castilrubio y la Zafrilla, no sacaba el ganado durante la montanera ni se mataban vacas. Andrés Hernández, vaquero de Guadalupe, también recuerda que pastaba con sus vacas en dehesas con monte durante todo el año sin ningún contratiempo. En las dehesas de propios, según el primer testigo citado (Canchal, Matilla y Carrascal), si se mataba una vaca por cada sesenta ${ }^{99}$.

Alonso Martín Collado sitúa el comienzo de la costumbre de matar vacas (una por rebaño) hacia 1497-1502. Su información parece precisa, puesto que

meter vacas ni carneros ni ovejas ni cabras, e que si meten en el dicho tienpo las dichas vacas que pueden matar una vaca e una ternera, e de las cabras e ovejas e carneros e puercos de cada rebaño dos o tres conforme a sus hordenanzas e carta ejecutoria"; lo sabe porque "a visto muchas vezes traer a la dicha villa vacas e carneros e ovejas, e dezian que los trayan de las dehesas del dicho condado" (ACG, caja 1315, $\mathrm{n}^{\circ} 1-2$, ff. 83v-84r).

97 "despues de vareada queda poca [bellota] e con los muchos puercos que andan... e ha visto que no comen los dichos ganados bacuno syno poca vellota" (AGS-CCP, leg. 11, n 393-4).

${ }^{98}$ AGS-CCP, leg. 11, no 393-4, ff. 1r-1v y 4r.

${ }^{99}$ AGS-CCP, leg. 11, no 393-4, ff. 3r; ACG, caja 1315, no 1-2, f. 51v. En un interrogatorio de 1532, Garcí López Blandón (Medellín, 80 años) señala que este uso estaría asentado desde "setenta años a esta parte", según "lo oyo desir a su padre e a sus aguelos que ansi lo avian visto husar e guardar en sus tienpos". Otras fuentes, más cercanas y precisas, no avalan esta información (ACG, caja 1315, n 1-2, ff. 87v-88r). 
se refiere a hechos sucedidos sólo dos décadas antes. En la sentencia del bachiller Chaherrero no aparece esta cuestión, aunque si al desacoto de la bellota. Sin embargo, la base legal de esta costumbre parece fundamentarse en su sentencia ${ }^{100}$. En las quejas de Medellín contra el conde y la Mesta en 1506 se alude al matar de las vacas e toros. En 1511, la Mesta se queja sobre el matar de los toros e vacas e novillos en las dehesas cavalleriles ${ }^{101}$. Los beneficios se repartirían sobre todo entre el concejo y los oficiales. Pedro de Torres (Medellín), indica que el concejo se lleva la mitad de la vaca y el cuero, regidores y alcaldes un cuarto y el mayordomo el menudo de la vaca o ternera ${ }^{102}$. La sentencia de Amarilla fija su reparto, según la costumbre, entre la villa, los regidores y los pobres ${ }^{103}$.

La ordenanza sobre la materia sólo alude al sacrificio de una vaca y una ternera del mayor hierro por cada rebaño de sesenta, pero también se aplica con el ganado ovino. Pedro Vázquez (Medellín) señala como se pueden matar cabras, ovejas, carneros o puercos. Entre 1529 y 1532, el monasterio de Guadalupe perdió en sus dehesas, al margen de los toros cogidos para festejos, seis vacas, veinte ovejas y dos yeguas ${ }^{104}$. Conservamos tres sentencias del alcalde Bernardino García relativas a las dehesas de Palacio, Vivares y Palazuelo. Entre el 3 y el 21 de octubre de 1531 se encuentran sesenta y tres, sesenta y una y más de sesenta reses y se matan tres vacas y dos terneras ${ }^{105}$. No siempre se sacrifican cabezas del mayor hierro por razones de inoperancia o clara enemistad política. Hacia 1543 ó poco antes, se sacrificó una vaca de Bartolomé Sánchez de la Higuera por sus diferencias con el conde ${ }^{106}$.

Los regidores, una vez se ha establecido esta costumbre, han procedido a matar vacas u otros animales durante la montanera. En las dehesas de Jarilla y Rinconcillo se mataron vacas a Hernán Guisado y Francisco Sánchez (Villanueva) en 1512 y entre esta fecha y 1532. Juan García (Villanueva) ha visto matar vacas en la Jarilla, Peral, Canchal, Torrevirote, Cuadrado y Torre de Caños ${ }^{107}$. En 1517, se recoge esta cuestión entre las reclamaciones de la Mesta contra el concejo de Medellín ${ }^{108}$.

El sacrificio de reses evolucionó tardíamente hacia su pago en dinero. Esto suponía un ahorro considerable para Medellín y permitía a los arrendata-

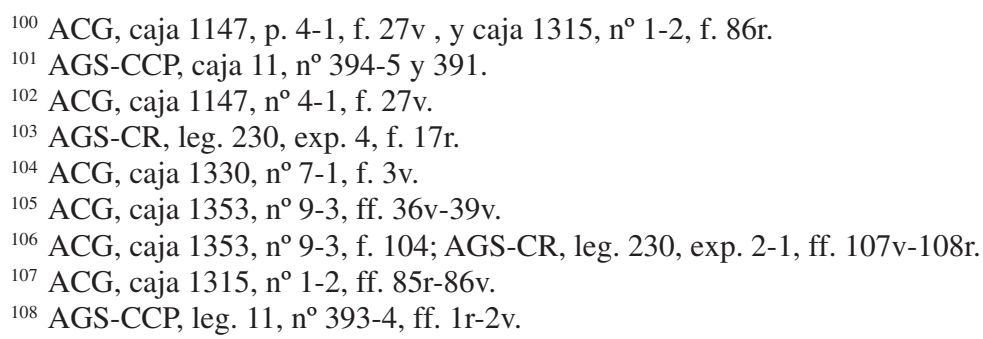


rios aprovechar el pasto y la bellota sin contratiempos. El monasterio de Guadalupe se ha ajustado tempranamente a esta forma de pago. Andrés Domínguez, que fue dos veces alcalde en Medellín, remonta el acuerdo al último cuarto del siglo XV o al primero del XVI, en tiempos del segundo conde de Medellín Juan Portocarrero ${ }^{109}$. Juan de Hervás indica que, por San Andrés, el mayoral del monasterio pagaba a los oficiales de Medellín, como vio algunas veces, el valor de una vaca y una ternera por la dehesa de Matilla. En 1522 y 1527-1528, no se mataron vacas en esta dehesa de propios por la razón indicada. Desde 1529, este acuerdo con el monasterio de Guadalupe no se ha respetado, como consta en diversos pleitos de la Chancillería de Granada. En una fecha indeterminada, Medellín y los demás propietarios de ganados concertaron acuerdos similares. Las razones para Medellín se sustentaban en la rentabilidad, puesto que matar las vacas generaba más gastos que beneficios económicos ${ }^{110}$.

Entre 1537-1538 y 1542-1543 se alterna el pago en dinero y el sacrificio o entrega del correspondiente animal. Se aprecian diferencias sustanciales entre el valor estimado de la renta de las vacas, casi setenta y cinco mil maravedís, y los ingresos reales, entre veintisiete y treinta y siete mil maravedís aproximadamente. Fernán López de Ávalos, procurador del concejo, estima para 1538-9 un fraude superior a los cuarenta mil maravedís. Alonso de San Pedro contestará que ese año sólo se cobraron en dinero las vacas (es decir, la mitad que correspondía al concejo) que constan en los ingresos concejiles ${ }^{111}$. Al margen del posible fraude, no encontramos ninguna explicación razonable para que no se compute ningún ingreso en algunos casos y en otros se maten vacas y se cobre dinero. Sin duda, estamos ante una costumbre variable y posiblemente ante beneficios no documentados de los oficiales concejiles. En todo caso, la renta de las vacas es una renta consolidada que ratifica la sentencia de Juan de Amarilla en 1540.

No hay una relación estrecha entre la capacidad ganadera de las dehesas y la cantidad asignada en esta renta. Es posible que la segunda esté en relación con la cantidad y calidad del monte. Tomando como base la valoración de esta renta en 1540-1541, cada vaca de hierba paga entre quinceveinte maravedís (Guadaperalejo, Rinconcillo, Castilrubio, Matilla, La Mata y Cuadradillo) o, más frecuentemente, entre cinco-diez (Canchal, Torre de Caños, Mezquita, Cuadrado, Guadaperal, Carrascal, Cabeza del Caballo y Palazuelo de los Frailes). Sólo en Torrevirote se paga una cantidad intermedia (11,43 mrs.).

${ }^{109}$ ACG, caja $1315, n^{\circ} 1-2$, f. 90v, caja $1353, n^{\circ} 9-3$, f. $213 v$, y caja $1353, n^{\circ} 9-4$, f. 178 r; en el mismo sentido, ACG, caja 1353, no 9-4, f. 81v y $127 \mathrm{v}$, y caja 1315 , nº 1-2, f. $51 \mathrm{v}$.

${ }^{110}$ AGS-CR, leg. 230, exp. 3, f. 22r.

111 AGS-CR, leg. 140, exp. 2, f. 267v y 279r. 


\begin{tabular}{|c|c|c|c|c|c|c|}
\hline \multicolumn{7}{|c|}{$\begin{array}{c}\text { Cuadro } \mathrm{n}^{0} 3 \\
\text { Medellín: renta de las vacas (1538-1543) -mrs.- }\end{array}$} \\
\hline Dehesas/concepto & $\begin{array}{l}1538- \\
1539\end{array}$ & $\begin{array}{l}1539- \\
1540\end{array}$ & $\begin{array}{l}1540- \\
1541\end{array}$ & $\begin{array}{r}1541- \\
1542 \\
\end{array}$ & $\begin{array}{r}1542- \\
1543 \\
\end{array}$ & $\begin{array}{c}\text { Estimac. } \\
(1540-1541)\end{array}$ \\
\hline Jarilla & *958 & & & & 2.000 & \\
\hline Torrevirote & $\begin{array}{r}4000+ \\
* 506 \\
\end{array}$ & 3.000 & 3.000 & 3.000 & 3.000 & 4.000 \\
\hline Canchal & $\begin{array}{r}6000+ \\
* 966 \\
\end{array}$ & 6.000 & 6.000 & 6.000 & 6.000 & 6.000 \\
\hline $\begin{array}{l}\text { Torre de Caños y } \\
\text { Fresneda }\end{array}$ & 8.000 & & & & & \\
\hline $\begin{array}{l}\text { Torre de Caños, Fres- } \\
\text { neda y Guadaperalejo }\end{array}$ & & 8.000 & 8.000 & 8.000 & 8.000 & \\
\hline Torre de Caños & & & & & & 5.000 \\
\hline Guadaperalejo & & & & & & 3.000 \\
\hline Rinconcillo & 2.000 & 2.000 & 2.000 & 2.000 & 2.000 & 3.100 \\
\hline Mezquita & 3.350 & 3.350 & 3.500 & 3.350 & 3.350 & 3.350 \\
\hline Cuadrado & 5.200 & $* 452$ & 3.000 & & & 5.200 \\
\hline Guadaperal & 4.200 & 4.300 & $* 460$ & $\begin{array}{r}4.300+ \\
* 479 \\
\end{array}$ & 4.300 & 4.000 \\
\hline Castilrubio & & & 3.000 & 3.000 & 3.000 & 3.000 \\
\hline Fresneda de Zapardiel & - & - & $* 506$ & - & - & \\
\hline Carrascal & & - & $* 416$ & - & & 3.500 \\
\hline Matilla & & - & -1 & - & 2.250 & 4.000 \\
\hline Cabeza del Caballo & & & & & & 4.000 \\
\hline La Mata & & & & & & 4.000 \\
\hline Palazuelo de los Frailes & & & & & & 3.000 \\
\hline Mata de Santa María & & & & & & 3.000 \\
\hline Cuadradillo & & & & & & 3.000 \\
\hline Hornillo del Canchal & & & & & & 3.000 \\
\hline Vivares & & & & & & 3.350 \\
\hline Valdegamas & & & & & & 3.000 \\
\hline Zafrilla & & & & & & 3.000 \\
\hline Arroyo de las Puercas & & & & & & - \\
\hline Cueros de las vacas & 1.836 & 340 & 1.020 & 375 & & \\
\hline TOTAL & 37.016 & 27.442 & 30.902 & 30.504 & 33.900 & 73.500 \\
\hline
\end{tabular}




\section{EL TERRAZGO CEREALISTA: RASTROJOS Y DERROTA DE MIESES}

El terrazgo cerealista y, en particular, los rastrojos adquieren una importancia creciente para el ganado a lo largo del siglo XV. El crecimiento demográfico, agrario y con seguridad también ganadero ha requerido una mayor integración agropecuaria y el consiguiente desarrollo de las hojas de cultivo $^{112}$. Las hojas han alcanzado un amplio desarrollo en la tierra de Medellín en el segundo cuarto del siglo XVI. Las fuentes, sin embargo, son poco explícitas cuando no permanecen calladas. Se documentan en Valdetorres y Villar, y de modo menos claro en Medellín, Mengabril y Don Benito ${ }^{113}$. Este cambio ha supuesto el paso de un aprovechamiento individual de los rastrojos a otro colectivo (derrota de mieses). En este contexto, el terrazgo cerealista adquiere una gran importancia entre los meses de junio, después de la recolección, y agosto. Se trata de un periodo en el que el alimento escasea. Parece existir una costumbre antigua por la que se cerraban después de la festividad de Santa Maria de Agosto, cuando cada propietario podía quemar sus rastrojos para hazer sus barvechos ${ }^{114}$. En este contexto de cambio se documenta una creciente conflictividad sobre su aprovechamiento ${ }^{115}$.

Antes de la elaboración de la ordenanza de los rastrojos de 1538, se estaba difundiendo su aprovechamiento comunal, lo que sería compatible con la permanencia del aprovechamiento privado. Es posible incluso que estemos ante una situación de cierta confusión, con nuevos usos y ordenanzas antiguas no derogadas. A mediados del siglo XVI, en Los Cerros (Valdetorres) y en tierras colindantes se practica desde tiempo ynmemorial la derrota de mieses ${ }^{116}$. Más precisa es una sentencia de 1520 en el conflicto que enfrenta a Medellín con el conde. Alonso de Monroy recibe veinte hanegadas junto al arroyo de Cagánchez, que después de la siega quedarán para pasto comun, como lo son todas las otras tierras del termino de la dicha villa de Medellin ${ }^{117}$. A juzgar por la sentencia, el aprovechamiento comunal de los rastrojos y la derrota de mieses estaban plenamente asentados en toda la jurisdicción a finales de la

\footnotetext{
${ }^{112}$ La relación entre el desarrollo de las hojas y la necesidad de compatibilizar el aprovechamiento agrario y pecuario se documenta con extraordinaria claridad en Arroyomolinos de Montánchez: D. García-Gil, Transformaciones agrarias, p. 94.

$113 \mathrm{~J}$. Clemente, El régimen agrario de Villar de Rena, pp. 9-11; AGS-CR, leg. 526, exp. 5, f. 43v (Mengabril), y leg. 140, exp. 2, f. 310r (Medellín); ACG, leg. actual 31, nº 1, f. 582r (Valdetorres); A. Bernal, Don Benito, p. 270.

${ }_{114}$ AGS-CR, leg. 87, exp. 14, f. 52v-53r.

115 Sobre las prendas realizadas en 1538, Don Benito alude a "sus hordenanças husadas guardadas y husos y costunbres ynmemoriales" (AGS-CR, leg. 510, exp. 18).

${ }^{116}$ ACG, leg. $31, n^{\circ} 1$, f. $427 \mathrm{v}$.

${ }^{117}$ ACG, leg. 1371, n 5, f. 30r.
} 
segunda década del siglo XVI. Esta costumbre también parece consolidada hacia 1528 en las tierras comunales que se conceden en los montes bravos ${ }^{118}$. En realidad, la ordenanza de rastrojos de 1538 no implanta la derrota de mieses ni supone ningún cambio radical sobre los usos agrarios vigentes en ese momento. Su única finalidad era impedir que la cabaña vecinal penetrase en los rastrojos antes de que se levantarán las hacinas, lo que constituía una fuente constante de daños y altercados ${ }^{119}$.

El desarrollo de la derrota de mieses no se ha realizado sin oposición. De hecho, hay un recuerdo nítido de los usos anteriores y en el segundo cuarto del siglo XVI pugnan dos concepciones sobre la explotación de los rastrojos. En 1539, Guareña señala que antiguamente cada vecino aprovechaba o vendía sus rastrojos ${ }^{120}$. Los datos se repiten sobre aquellos que, pastando sus propios rastrojos, se sorprenden de ser prendados o se quejan de que otros los aprovechen. Sin duda, las ordenanzas han cambiado más rápidamente que los usos agrarios. En Don Benito, en 1538, Pedro Valdés denuncia que un hijo de Francisco Rodríguez le había comido su rastrojo con unos puercos. Hacia 15361537, se prendaron seis puercos de Sebastián de Oliva en su propio rastrojo ${ }^{121}$. Ese mismo año, Don Benito denuncia que se ha hecho lo mismo con diversos vecinos por la aplicación de la ordenanza citada ${ }^{122}$. En el pleito que en 1543 enfrenta a Medellín y al conde se enumeran las prendas realizadas desde la redacción de la ordenanza de rastrojos de 1538. Se ha prendado en sus propias heredades a Sebastián del Oliva, ya citado, Pedro Alonso Cortés, Sebastián de Vargas o Lázaro Sánchez, todos ellos vecinos de Guareña ${ }^{123}$.

A mediados del siglo XVI, las ordenanzas de Don Benito se ajustan estrictamente a la ordenanza de rastrojos de Medellín. El rastrojo es aprovechado por el ganado del propietario hasta que se levanta el cereal, cuando queda libre e pasto comun para todos ${ }^{124}$. Mengabril, sin embargo, ofrece en esas mismas fechas una situación diferente. Los rastrojos parecen aprovecharse o venderse por los propietarios. Es posible que todo esto sólo tuviera validez durante la recolección y antes de que se hubieran alzado las hacinas ${ }^{125}$. Nuevas y viejas formas de explotación de los rastrojos perviven a mediados del siglo

\footnotetext{
${ }_{118}$ A. Cat. Plasencia, leg. 94, $n^{\circ}$ 27, f. 11r.

119 En relación con esta problemática había muerto un hijo de Alvar García. Diversos testigos estiman que la nueva normativa permitirá cosechar, al menos, mil fanegas adicionales de cereal (AGS-CR, legs. 510, exp. 18, ff. 16v-23v, y 230, exp. 3, f. 20v).

${ }^{120}$ AGS-CR, leg. 230, exp. 4, f. 25 r.

${ }^{121}$ AGS-CR, leg. 230, exp. 2-1, f. 66r, 98v y 102v.

${ }^{122}$ AGS-CR, leg. 510, exp. 18, f. 35r.

${ }^{123}$ AGS-CR, leg. 230, exp. 2 bis, ff. 99r y 101v, y exp. 2-1, f. 103r-v.

${ }^{124}$ A. Bernal, Don Benito, p. 256.

125 J. Clemente, Ordenanzas de Mengabril, pp. 643-644.
} 
XVI dentro de una casuística compleja. Las líneas de cambio, en beneficio del aprovechamiento comunal de los rastrojos, se presentan sin embargo perfectamente perfiladas.

\section{ESPACIO PECUARIO Y CRECIMIENTO ECONÓMICO}

Entre principios del siglo XV y el tercer cuarto del XVI se desarrolla un proceso de crecimiento demográfico y económico que produjo una creciente presión sobre el espacio ${ }^{126}$. Disponemos de datos parciales que no ofrecen ninguna duda. Hacia 1450, Miajadas contaba con sesenta-setenta vecinos y Valdetorres con alrededor de cuarenta ${ }^{127}$. En el alarde de 1502, aparecen, además de los combatientes a caballo, 1.955 lanceros y 51 ballesteros (261 en Miajadas y 137 en Valdetorres) $)^{128}$. Para 1501, Juan González, vecino de Miajadas, calcula una población, un tanto exagerada posiblemente, de mas de tres mill vesinos para toda la tierra ${ }^{129}$. En 1530, la jurisdicción cuenta con 2.578 vecinos pecheros ${ }^{130}$. En las dos décadas siguientes la población parece estabilizarse: Medellín cuenta con algo más de cuatrocientos vecinos pecheros; Miajadas, con quinientos o algo menos; Villar, con unos sesenta; y Mengabril, con unos doscientos ${ }^{131}$. Todo indica que el crecimiento demográfico ha sido muy importante en la segunda mitad del XV y se ha ralentizado en la primera mitad del XVI.

Esta dinámica expansiva se extendió a los cultivos y a las cabañas ganaderas, afectando negativamente al bosque ${ }^{132}$. La situación de partida, con

${ }^{126}$ Estamos ante una dinámica muy difundida en la corona de Castilla. Citaremos sólo algunos ejemplos regionales: $\mathrm{M}^{\mathrm{a} A}$. Sánchez Rubio, El concejo de Trujillo, p. 55; D. Rodríguez, La Orden de Santiago en Extremadura, pp. 81 y 84; F. Mazo, El condado de Feria (1394-1505), pp. 521-524; M.A. Melón, A. Rodríguez, Crecimiento demográfico y extensión de cultivos en Coria, pp. 171-173; D. García-Gil, Transformaciones agrarias en la Tierra de Montánchez, p. 81 .

127 J. Clemente, La tierra de Medellín (1234-c. 1450), p. 47.

${ }^{128}$ M.A. Ladero, La caballería y la población de Extremadura, p. 170.

${ }^{129}$ AHN, Mesta, caja $121, n^{\circ} 1$, f. $32 \mathrm{v}$.

130 A. Bernal, Poblamiento, transformación y organización social del espacio extremeño, p. 150.

${ }^{131}$ AGS-CR, leg. 230, exp. 2-1, f. 55v, exp. 6, f. 150v, y exp. 3, f. 9r; AGS-CR, leg. 526, exp. 5 , ff. $45 \mathrm{v}$ y $50 \mathrm{v}$.

${ }_{132}$ Pedro Martín Peinado alude, a mediados del siglo XVI, al periodo lejano en que "avia otros muchos [montes] en todo el condado e abundançia de pasto e pocos ganados" (ACG, leg. 31, no 1, f. 429r). En el siglo XV y primer cuarto del XVI, se documenta un crecimiento de la cabaña trashumante en la corona de Castilla, aunque no podemos precisar su incidencia en la tierra de Medellín: J.-P. le Flem, Las cuentas de la Mesta (1510-1709), pp. 27, 32 y 38; $\mathrm{M}^{\mathrm{a}} \mathrm{C}$. Gerbet, Un élevage original au Moyen Âge, pp. 265-267; F. Ruiz, Pastos y ganaderos en Castilla, pp. 50-57. 
una bajísima densidad poblacional, permitió que este proceso se desarrollase con una limitada conflictividad. Sólo a finales del periodo moderno el hambre de tierras supondrá una amenaza para el aprovechamiento ganadero de las dehesas ${ }^{133}$.

Las rozas debieron proliferar al ritmo del crecimiento poblacional. Los vecinos de Valdetorres ya pagaban un censo por las rozas de los Rengeles a Pedro Mejía $(+1462)^{134}$. Hacia 1500 , los Cerros, montes por abrir cercanos a esta aldea, estaban convirtiéndose en tierras de sembradura ${ }^{135}$. Las rozas empiezan a aparecer como linderos o como espacios de cierta entidad que dejan un registro toponímico en el último cuarto del siglo $X^{136}$. El sistema de concesión concejil de tierras parece claramente definido a principios del siglo $\mathrm{XVI}^{137}$.

Aunque la información es poco precisa, el estrechamiento de los ejidos por las apropiaciones de cercas y la ampliación de algunas dehesas boyales (Valdetorres, quizás las aldeas con dos dehesas) han debido desarrollarse con cierta fuerza desde la segunda mitad del siglo XV. Muchas de las cercas de Miajadas, objeto de pleito en 1538-9, se debieron ocupar como poco en el último cuarto del siglo XV. La mujer de Alonso Hernández Bermejo alega la posesión de su alcácer por diversos propietarios durante más de cincuenta años $^{138}$. No se trata de un caso excepcional.

Hacia 1500 no se detectan indicios serios de escasez de espacio ${ }^{139}$. En la primera mitad del siglo XVI, pese a la ralentización del crecimiento demográfico, se producen manifestaciones más claras sin que se llegue a situaciones críticas ${ }^{140}$. El proceso sobre las cuentas concejiles (1537-1543) nos permite disponer de una imagen precisa sobre el crecimiento del espacio agrario. El concejo de Medellín concede en los montes bravos veintidós rozas en

${ }_{133}$ J.A. Ruiz, Evolución de la propiedad de la tierra, pp. 85-180; idem, La lucha por la tierra en Don Benito a finales del siglo XVIII.

${ }^{134}$ ACG, caja $1950, n^{\circ} 6$, f. 200r.

${ }_{135}$ ACG, caja $31, n^{\circ} 1$, f. 429r.

${ }_{136}$ AGS-CCP, leg. 11, no 341, a. 1500; ACG, caja 1950, nº 6, f. 62r, a. 1480.

${ }^{137}$ ACG, leg. 643, no 1, ff. 8r-9r (roza de diez fanegas concedida a Juana Hernández la Pajuela en Mengabril).

${ }^{138}$ AGS-CR, leg. 231, no 2, f. 71v.

${ }^{139}$ Sin embargo, desde el tercer cuarto del siglo XV empieza a regularse más estrechamente en la región el aprovechamiento del bosque, lo que afectará sensiblemente a los trashumantes: C. Fernández-Daza, La actividad ganadera en Trujillo, p. 102; J. Clemente, La evolución del medio natural, pp. 23-24.

${ }^{140}$ El reinado de los Reyes Católicos parece marcar el comienzo de una clara contradicción entre la economía campesina de base agropecuario y la ganadería trashumante: A. García Sanz, Los privilegios mesteños, p. 77; F. Marín, Los Reyes Católicos y el Honrado Concejo de la Mesta, p. 133. 
1539-1540, tres en 1540-1541, trece en 1541-1542 y once en $1542-1543^{141}$. Todas ellas, cuando se precisa su extensión, tienen doce fanegas. Esto supone la concesión de algo menos de ciento cincuenta fanegas al año. El concejo de Medellín parece disponer de importantes reservas de tierra a mediados del siglo XV. En todo caso, no parece que por su densa vegetación hayan sido objeto de una previa explotación ganadera.

La presión sobre el espacio se manifiesta también en el interés de algunos concejos en el aprovechamiento de las dehesas ${ }^{142}$. El ejemplo de Miajadas, sin embargo, parece responder a circunstancias muy especiales. Hacia principios del siglo XVI, esta aldea arrienda por dos años la dehesa de propios del Canchal ${ }^{143}$. En 1532, ha extendido sus cultivos, aunque no podemos precisar su entidad, a las dehesas colindantes de Hornillos, Casalcampo, Canchal, Mezquita o Vivares ${ }^{144}$. Miajadas arrienda posteriormente el Canchal (1534; 1538-1542), Ventoso (1537-1538, 1548 -agostadero-) o Casalcampo (1538). En 1538-1540, vecinos de Miajadas, sobre todo, y Almoharín tenían arrendada a pasto y labor $3 / 8$ de la dehesa de Cuadrado y labraban en ella con diez yuntas $^{145}$. Don Benito explotaba desde hacía más de un siglo la Veguilla. En 1539, su ganado pastaba la dehesa de Torrevirote ${ }^{146}$.

Otra manifestación del crecimiento agrario, y del consiguiente aumento del número de bueyes, es la insuficiencia creciente de las dehesas boyales. Se documentan situaciones de estrechez hacia mediados del siglo XVI. Las situaciones de Medellín, Guareña o Mengabril, ya precisadas, son suficientemente ilustrativas. En Guareña se señala el aumento de vecinos y bueyes. Sin embargo, la población entre principios del XVI y 1530, debido sin duda a la crisis de 1505-7, no parece haberse incrementado sustancialmente. Es posible que, como en otros lugares de la jurisdicción, tampoco lo hiciese en las dos décadas siguientes.

También a mediados del siglo XVI ha alcanzado su madurez el cercamiento de gran parte de los ejidos. Hemos indicado la enorme difusión de las cercas en el ejido de Miajadas. En la probanza de la tierra se indica que se dan cercas en el ejido para senbrar alcaçer para sus bueyes y bestias porque en el dicho lugar no se pueden sustentar los ganados de otra manera ${ }^{147}$. Cre-

\footnotetext{
${ }^{141}$ AGS-CR, leg. 140, exp. 2-I, ff. 174-180v; 185r-197r, 201r-210r, y 223v-226r.

${ }^{142}$ Se documenta igualmente en el Campo de Calatrava desde finales del siglo XV: J. LópezSalazar, Mesta, pastos y conflictos en el Campo de Calatrava, pp. 96-99.

${ }^{143}$ AGS-CR, leg. 39, no 5, ff. $12 \mathrm{v}-13 \mathrm{r}$.

${ }_{144}$ A. Cat. Plasencia, leg. $109, \mathrm{n}^{\circ} 6$.

${ }^{145}$ AGS-CR, leg. 87, exp. 14, f. 37r; leg. 140, exp. 2; leg. 230, exp. 6, ff. 174r y 180r-181r; leg. 231, exp. 6, f. 78r; leg. 631, no 10, ff. 21r-v; y leg. 231, exp. 10.

${ }^{146}$ AGS-CR, leg. 140, exp. 2, f. 10r.

${ }^{147}$ AGS-CR, leg. 230, exp. 2-1, ff. 109v y 110r.
} 
cimiento agrario y demográfico, insuficiencia de las dehesas boyales y proliferación de las cercas aparecen, de este modo, estrechamente vinculados.

La coyuntura alcista que se desarrolla entre principios del siglo XV y finales del siglo XVI ha generado una presión creciente sobre el espacio. El aumento del número de bueyes ha condicionado las ampliaciones de las dehesas boyales y la proliferación de alcáceres. Los terrenos de pastos no han sufrido una disminución significativa aunque hay que considerar la proliferación de cercas en los ejidos y el aprovechamiento agrario de algunas dehesas. Las rozas entregadas por el concejo, en su condición de montes bravos, no parece que de modo general hayan tenido una previa explotación pecuaria. Hacia 1550, y pese a la dinámica indicada, las tensiones parecen limitadas y no han originado ninguna clara conflictividad. Las cabañas vecinales no han conocido ninguna limitación ${ }^{148}$.

\section{CONCLUSIONES}

El espacio pecuario de Medellín queda en gran medida perfilado en el proceso de ocupación cristiana del espacio que se desarrolla entre los siglos XIII y XIV. La enorme difusión espacial del adehesamiento se mantendrá como una realidad constante hasta finales del antiguo régimen. Esto reduce el peso cuantitativo de los espacios comunales y baldíos, que no alcanzan una extensión comparable.

Dos elementos aparecen con nitidez en el periodo estudiado: la importancia de los derechos comunales en las dehesas, que ahora pueden estudiarse con precisión, y la utilización de los comunales como fuente de financiación de los concejos aldeanos. El primer aspecto requeriría una encuesta sistemática al menos en toda la submeseta meridional. En Medellín, los propietarios de dehesas sólo terminarán acotando el pasto. Los vecinos mantienen su derecho sobre el aprovechamiento de recursos como la madera y la bellota. Esta realidad, además de explicar la aparición de cargas como la renta de las vacas, a satisfacer en las dehesas con monte, permite el desarrollo de una importante cabaña porcina. No se trata de una realidad circunscrita a Medellín, aunque sólo estudios sistemáticos podrán precisar su difusión.

${ }^{148}$ En el siglo XV y primera mitad del XVI se empiezan a limitar las cabañas vecinales: A. Huetz de Lemps, Les terroirs en Vieille Castille et Léon, p. 247-248; J.L. Martín Martín, Evolución de los bienes comunales en el siglo XV, p. 45; J.C. Martín Cea, El mundo rural castellano, pp. 124-125; H. Casado, Señores, mercaderes y campesinos, pp. 224 y 230; R.H. Oliva, La Tierra de Campos, p. 175; M. Diago, Aprovechamiento de baldíos y comunales, p. 430; F.J. Goicolea, Haro, p. 87; S. Hernández, Agricultura, ganadería y transhumancia, pp. 69-71. 
La utilización de los comunales por las aldeas para su financiación no puede entenderse sin su maduración institucional, demográfica y social. La casi total ausencia de propios les obliga a explotar estos recursos. Estos espacios mantienen en todo caso su condición comunal.

Entre mediados del siglo XV y mediados del XVI, se producen cambios importantes en un contexto de intenso crecimiento demográfico y agrario. Se van a ampliar las dehesas boyales a la vez que se regula de modo más preciso su explotación. Los ejidos sufren una profunda transformación. Se desarrollan las cercas, lo que reduce el espacio disponible para la cabaña estante. Al menos en Miajadas, el caso mejor documentado, ambos fenómenos están claramente relacionados: los alcáceres de los ejidos subvienen, ante la insuficiencia de la dehesa boyal, al mantenimiento del ganado de labranza. Se empieza a configurar en este momento de forma definitiva la orla de cercados que rodea los espacios de hábitat. El desarrollo de la derrota de mieses, y la consiguiente ordenación en hojas de terrazgo cerealista, aspectos sobre el que las fuentes no son muy precisas, permitió una mejor explotación de los rastrojos. Algunos concejos aldeanos muestran un interés creciente en acceder a la explotación de algunas dehesas. La capacidad ganadera del espacio adehesado no parece que sufriera por ello una reducción drástica. Los indicios de presión sobre el espacio proliferan, pese a la ralentización del crecimiento demográfico, en la primera mitad del siglo XVI. No se documenta, sin embargo, una situación de hambre de tierras como en el siglo XVIII.

\section{BIBLIOGRAFÍA}

Andrada Martín, José Manuel, Los propios, comunes y baldíos de Mérida en el siglo XVI, Mérida, UNED-Mérida, 1986.

Asenjo González, María, Segovia. La ciudad y su tierra a fines del medievo, Segovia, Diputación de Segovia, 1986.

Bernal Estévez, Ángel, Poblamiento, transformación y organización social del espacio extremeño (siglos XIII al XV), Mérida, Editora Regional de Extremadura, 1998.

Bernal Estévez, Ángel, Don Benito en la primera mitad del siglo XVI, "Boletín de la Real Academia de Extremadura de las Letras y las Artes" 12 (2002), pp. 181-295.

Casado Alonso, Hilario, Señores, mercaderes y campesinos. La comarca de Burgos a fines de la Edad Media, Madrid, Junta de Castilla y León, 1987.

Cerro Herranz, $\mathrm{M}^{\mathrm{a}}$ Filomena, Documentación del monasterio de Guadalupe. Siglo XIV, Badajoz, Diputación de Badajoz, 1987. 
Clement, Vicent, Spanish Wood Pasture: Origin and Durability of an Historical Wooded Landscape in Mediterranean Europe, "Environment and History" 14 (2008), pp. 67-87.

Clemente Ramos, Julián, La evolución del medio natural en Extremadura (c. 1142-c. 1525), en El medio natural en la España medieval. Actas del I Congreso sobre ecohistoria e historia medieval, Cáceres, Universidad de Extremadura, 2000, pp. 15-56.

Clemente Ramos, Julián, Valdetorres, de dehesa a aldea (1409-1510). Poblamiento, conflicto y poder en la tierra de Medellín, "Studia Historica. Historia Medieval" 20-21 (2002-2003), pp. 47-72.

Clemente Ramos, Julián, Las ordenanzas de Mengabril de 1548, "Revista de Estudios Extremeños" 60/2 (2004), pp. 597-650.

Clemente Ramos, Julián, El vaqueamiento de las dehesas de Medellín (1460), "Norba. Revista de Historia" 18 (2005), pp. 137-146.

Clemente Ramos, Julián, La organización del terrazgo agropecuario en Extremadura (siglos XV-XVI), "En la España Medieval" 28 (2005), pp. 49-80.

Clemente Ramos, Julián, Martín Sancho (siglos XIV-XVI). Un despoblado bajomedieval en la tierra de Medellín, "Hispania. Revista Española de Historia" 46/223 (2006), pp. 483-500.

Clemente Ramos, Julián, La tierra de Medellín (1234-c. 1450). Dehesas, ganadería y oligarquía, Badajoz, Diputación de Badajoz, 2007.

Clemente Ramos, Julián, La explotación económica del Campo Arañuelo y la economía rural de la tierra de Plasencia a mediados del siglo XV, "Anuario de Estudios Medievales" 39/1 (2009), pp. 245-274.

Clemente Ramos, Julián, Pautas de estructuración y fosilización de los paisajes agrarios medievales. Reflexiones e hipótesis, en El paisaje rural en Andalucía occidental durante los siglos bajomedievales. Actas de las I Jornadas Internacionales sobre Paisajes Rurales en Época Medieval, Cádiz, Universidad de Cádiz, 2011, pp. 173-191.

Clemente Ramos, Julián, El régimen agrario de Villar de Rena a mediados del siglo XVI, "Rivista di Storia dell'Agricoltura" 52/2 (2012), pp. 1-19.

Coronas Vida, Luis Javier, La economía agraria en las tierras de Jaén (15001650), Granada, Universidad de Granada, 1994.

Diago Hernando, Máximo, Aprovechamiento de baldíos y comunales en la Extremadura soriana a fines de la Edad Media, "Anuario de Estudios Medievales" 20 (1990), pp. 413-436.

Diago Hernando, Máximo, La aplicación en la Sierra soriana del derecho de posesión mesteño a los agostaderos durante el siglo XVII, "Estudios Agrosociales y Pesqueros" 195 (2002), pp. 61-80. 
Diago Hernando, Máximo, El acceso a las dehesas de La Serena por los ganaderos trashumantes sorianos, 1590-1650, "Historia agraria. Revista de Agricultura e Historia Rural" 23 (2001), pp. 55-78.

Fernández Nieva, Julio, Badajoz y su tierra en tiempos de Hernán Cortés, en Hernán Cortés y su tiempo. V Centenario (1485-1985), Mérida, Editora Regional de Extremadura, 1987, vol. 1, pp. 123-131.

Fernández-Daza Alvear, Carmen, La actividad ganadera en Trujillo durante la baja Edad Media, en Trashumancia y cultura pastoril en Extremadura, Mérida, 1993, pp. 89-105.

Flem, Jean-Paul le, Las cuentas de la Mesta (1510-1709), "Moneda y Crédito" 121 (1972), pp. 23-104.

García Martín, Pedro; Sánchez Benito, José María, Arbitrios locales sobre propiedad semoviente en Castilla durante los siglos XIV y XV, "En la España Medieval", 8 (1986), pp. 399-412.

García Oliva, $\mathrm{M}^{\mathrm{a}}$ Dolores, Orígenes y expansión de la dehesa en el término de Cáceres, "Studia Histórica. Historia Medieval" 4 (1986), pp. 77-100.

García Oliva, $\mathrm{M}^{\mathrm{a}}$ Dolores, Organización económica y social del concejo de Cáceres y su tierra en la Baja Edad Media, Cáceres, Diputación de Cáceres, 1990.

García Sanz, Ángel, Los privilegios mesteños en el tiempo, 1273-1836: una revisión de la obra de Julius Klein, en Mesta, trashumancia y lana en la España moderna, Barcelona, Crítica, 1998, pp. 65-89.

García-Gil, Diego, Transformaciones agrarias en la Tierra de Montánchez en el siglo XVI, en Historia moderna, historia en construcción. Economía, mentalidades y cultura, Lérida, Milenio, 1999, vol. I, pp. 77-102.

Gerbet, $\mathrm{M}^{\mathrm{a}}$-Claude, Un élevage original au Moyen Âge: la péninsule Ibérique, Biarritz, Atlántica, 2000.

Goicolea Julián, Francisco Javier, Haro: una villa riojana del linaje Velasco a fines del Medievo, Logroño, Instituto de Estudios Riojanos, 1999.

Hernández Vicente, Severiano, Agricultura, ganadería y transhumancia en el concejo de Benavente durante el siglo XV y la primera mitad del XVI, en Actas del Primer Congreso de Historia de Zamora, Zamora, Instituto de Estudios Zamoranos Florián de Ocampos, 1991, vol. III, pp. 53-71.

Huetz de Lemps, Alain, Les terroirs en Vieille Castille et Léon: un type de structure agraire, "Annales ESC" 17/2 (1962), pp. 239-251.

Izquierdo Benito, Ricardo, Precios y salarios en Toledo durante el siglo XV (1400-1475), Toledo, Caja de Ahorro Provincial, 1983.

Ladero Quesada, Miguel Ángel, Donadíos en Sevilla. Algunas notas sobre el régimen de la tierra hacia 1500, "Archivo hispalense" 59/181 (1976), pp. 19-92. 
Ladero Quesada, Miguel Ángel, La caballería y la población de Extremadura según los alardes de 1502, "Norba. Revista de Historia" 17 (2004), pp. 157-186.

Lop Otín, M $\mathrm{M}^{\mathrm{a}} \mathrm{J}$, Un ejemplo del proceso señorializador extremeño: el señorío de Capilla (siglos XIII-XVI), "En la España Medieval" 13 (1990), pp. 207-232.

López-Salazar Pérez, Jerónimo, Mesta, pastos y conflictos en el Campo de Calatrava durante el siglo XVI, Madrid, CSIC, 1987.

López-Salazar Pérez, Jerónimo, Las dehesas de la Orden de Calatrava, en Las órdenes militares en el Mediterráneo occidental (siglos XII-XVIII), Madrid, Casa de Velázquez - Instituto de Estudios Manchegos, 1989, pp. 249-290.

Luis López, Carmelo, La comunidad de villa y tierra de Piedrahíta en el transito de la Edad Media a la moderna, Ávila, Diputación de Ávila, 1987.

Mackay, Angus, Las alteraciones monetarias en la Castilla del siglo XV: la moneda de cuenta y la historia política, "En la España Medieval" 1 (1980), pp. 237-248.

Mangas Navas, José Manuel, El régimen comunal agrario de los concejos de Castilla, Madrid, Ministerio de Agricultura, 1981.

Marín Barriguete, Fermín, Los Reyes Católicos y el Honrado Concejo de la Mesta. Una desmitificación necesaria, "Cuadernos de Historia Moderna" 13 (1992), pp. 109-142.

Marín Barriguete, Fermín, La configuración institucional del honrado concejo de la Mesta: los Reyes Católicos y los privilegios ganaderos, en Mesta, trashumancia y vida pastoril, Madrid, Crítica, 1994, pp. 67-92.

Martín Cea, Juan Carlos, El mundo rural castellano a fines de la Edad Media. El ejemplo de Paredes de Nava en el siglo XV, Valladolid, Junta de Castilla y León, 1991.

Martín Martín, José Luis, Evolución de los bienes comunales en el siglo XV, "Studia Historica. Historia Medieval" 8 (1990), pp. 7-46.

Mazo Romero, Fernando, El condado de Feria (1394-1505). Contribución al estudio del proceso señorializador en Extremadura durante la Edad Media, Badajoz, Diputación de Badajoz, 1980.

Melón Jiménez, Miguel Ángel y Rodríguez Grajera, Alfonso, Crecimiento demográfico y extensión de cultivos en Coria y su tierra durante el siglo XVI, "Norba. Revista de Historia" 6 (1985), pp. 171-174.

Melón Jiménez, Miguel Ángel, Extremadura en el Antiguo Régimen. Economía y sociedad en tierras de Cáceres, 1700-1814, Cáceres, Editora Regional de Extremadura, 1989. 
Monsalvo Antón, José María, Espacios de pastoreo de la Tierra de Ávila: algunas consideraciones sobre tipos y usos de los paisajes ganaderos bajomedievales, "Cuadernos Abulenses" 31 (2002), pp. 139-196.

Oliva Herrer, Rafael Hipólito, La Tierra de Campos a fines de la Edad Media. Economía, sociedad y acción política campesina, Valladolid, Universidad de Valladolid, 2002.

Pelegrí Pedrosa, Luis Vicente y Martín Rubio, Ángel David, Tierra y sociedad en La Serena en el siglo XVIII, Badajoz, Diputación de Badajoz, 2002.

Pérez Romero, Emilio, Patrimonios comunales, ganadería trashumante y sociedad en la tierra de Soria, siglos XVIII-XIX, Valladolid, Junta de Castilla y León, 1996.

Rodríguez Blanco, Daniel, La Orden de Santiago en Extremadura en la baja Edad Media (siglos XIV y XV), Badajoz, Diputación de Badajoz, 1985.

Rodríguez-Picavea Matilla, Enrique: La ganadería en la Castilla medieval. Una revisión historiográfica, "Medievalismo" 8 (1998), pp. 111-153

Ruiz Martín, Felipe, Pastos y ganaderos en Castilla: la Mesta, 1450-1600, en Mesta, trashumancia y lana en la España moderna, Barcelona, Crítica, 1998, pp. 391-418.

Ruiz Rodríguez, Juan Ángel, Evolución de la propiedad de la tierra en el partido de Don Benito, 1750-1880, Badajoz, Diputación de Badajoz, 2010.

Ruiz Rodríguez, Juan Ángel, La lucha por la tierra en Don Benito a finales del siglo XVIII, Don Benito, Ayuntamiento de Don Benito, 2004.

Salomon, Noël, La vida rural castellana en tiempos de Felipe II, Barcelona, Planeta, 1973.

Sánchez Rubio, $\mathrm{M}^{\mathrm{a}}$ Ángeles, El concejo de Trujillo y su alfoz en el tránsito de la Edad Media a la Edad Moderna, Cáceres, Universidad de Extremadura, 1993.

Suárez Álvarez, María Jesús: La villa de Talavera y su tierra en la Edad Media, 1369-1504, Oviedo, Universidad de Oviedo, 1982. 


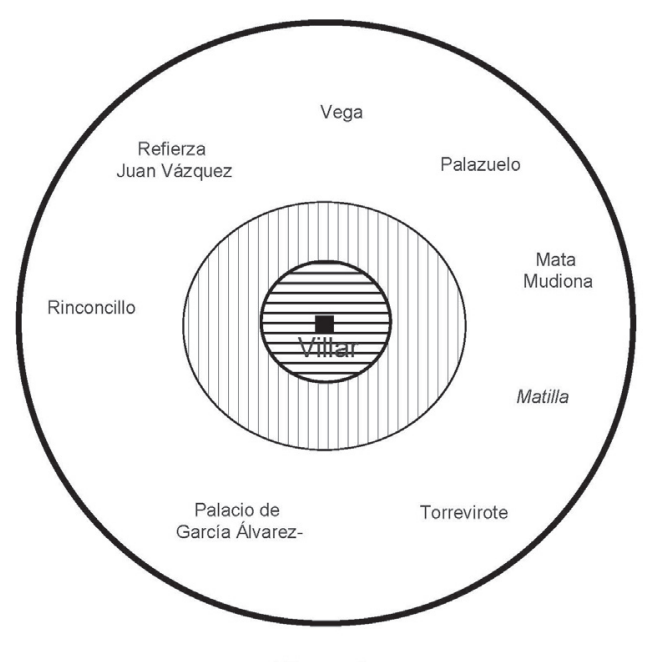

Mapa 1

Terrazgo de Villar de Rena (c. 1550).

Reconstrucción ideal

\begin{tabular}{|c|c|c|c|}
\hline 口 & Aldea & & espacio adehesado \\
\hline & Espacio Agrario (hojas-ejido) & Vega & Dehesa \\
\hline & Baldios y ejidos & Matilla & Propio adehesado \\
\hline
\end{tabular}




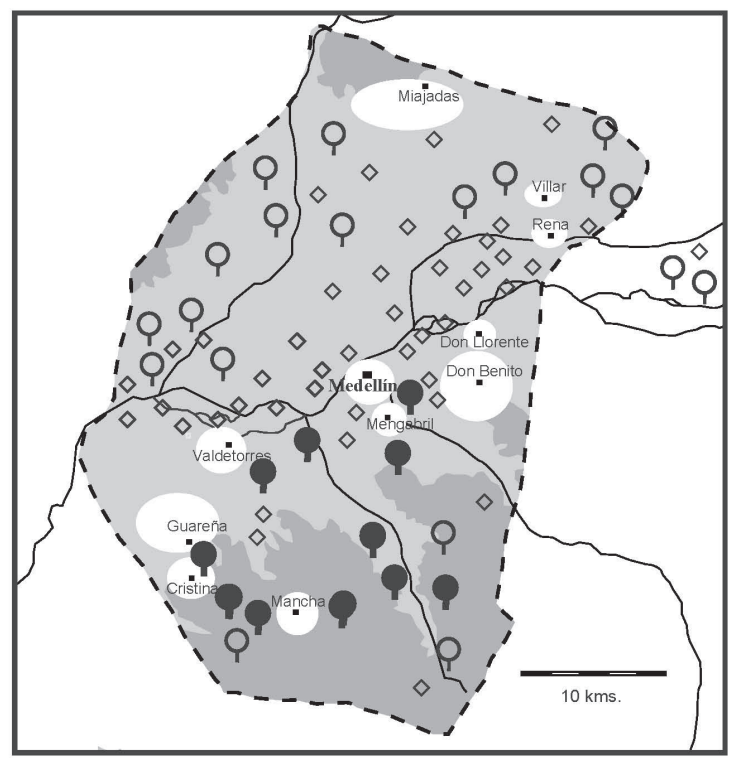

Mapa 2

El espacio pecuario en Medellín

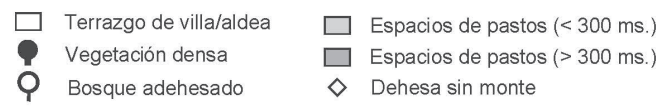

Fecha de recepción del artículo: enero 2012

Fecha de aceptación y versión final: enero 2013 